Article

\title{
Retrieval of Soil Moisture Content Based on a Modified Hapke Photometric Model: A Novel Method Applied to Laboratory Hyperspectral and Sentinel-2 MSI Data
}

\author{
Yuan Zhang ${ }^{1,+}$, Kun Tan ${ }^{1,2,3, *,+} \oplus$, Xue Wang ${ }^{2,3}$ and Yu Chen ${ }^{1}$ \\ 1 Key Laboratory for Land Environment and Disaster Monitoring of NASG, China University of Mining and \\ Technology, Xuzhou 221116, China; ts18160052a31@cumt.edu.cn (Y.Z.); chenyu@cumt.edu.cn (Y.C.) \\ 2 Key Laboratory of Geographic Information Science (Ministry of Education), East China Normal University, \\ Shanghai 200241, China; xwang@geo.ecnu.edu.cn \\ 3 School of Geographic Sciences, East China Normal University, Shanghai 200241, China \\ * Correspondence: tankun@geo.ecnu.edu.cn; Tel.: +86-021-5434-1227 \\ $+\quad$ Y.Z. and K.T. contributed equally to this work.
}

Received: 6 June 2020; Accepted: 10 July 2020; Published: 13 July 2020

check for updates

\begin{abstract}
Soil moisture is the crucial carrier of the global hydrologic cycle and the dynamic energy balance regulation process. Therefore, it is of great significance to monitor surface soil moisture content (SMC) accurately for the study of the natural ecological environment. The Hapke model is the most widely used photometric model in soil remote sensing research, but the development of this model is limited by the lack of valid multi-angular data. The main innovations of this paper have two aspects: (1) A novel soil moisture retrieval approach based on the Hapke (SMR-Hapke) model is derived by exploring the relationship between single scattering albedo (SSA) and SMC on the optical bands from 400 to $2400 \mathrm{~nm}$. The performance of the proposed model was verified on a dataset consisting of four different soil samples, and the experimental results indicated that the inverted soil moisture from SMR-Hapke model coincided with the measurement values, with the $R^{2}$ being generally more than 0.9 in the solar domain. (2) The SMR-Hapke model has been reduced to a linear form on the SWIR field and a physically-based normalized difference soil moisture index NDSMI Hapke has been proposed. Based on the laboratory-based hyperspectral data, we compared the performance of $N D S M I_{\text {Hapke }}$ with other traditional soil moisture indices using linear regression analysis, and the results demonstrate that the proposed $N D S M I_{\text {Hapke }}$ had a great potential for estimating SMC with $R^{2}$ values of 0.88 . Finally, high-resolution SMC map was produced by combining the Sentinel-2 MSI data with $N D S M I_{\text {Hapke }}$. This study provides a novel extended Hapke model for the estimation of surface soil moisture content.
\end{abstract}

Keywords: soil moisture content; Hapke photometric model; reflectance spectroscopy; Sentinel-2 MSI

\section{Introduction}

Soil moisture, one of the main ingredients of terrestrial ecosystems, links the global energy and hydrologic cycles by modulating the partitioning of sensible and latent heat fluxes [1], and profoundly affects the spatio-temporal variation of climatic conditions [2]. The monitoring of surface soil moisture content (SMC) can provide key information for precision agriculture [3] and a reference for regional hydrological studies [4,5]. Although traditional manual methods show a high accuracy in estimating soil moisture, it is difficult to reflect the spatial distribution of SMC at the macro level with expensive in situ measurements and a time-consuming spatial sampling process. As a technology for observing the 
Earth, many low-cost and timely remote sensing methods have been developed to realize the dynamic monitoring of SMC in large areas [6].

The main SMC retrieval methods can be classified into two major categories, based on the difference of the spectral response principles: microwave remote sensing methods and optical remote sensing methods. Microwave remote sensing systems have achieved significant success in recent years, including the Advanced Microwave Scanning Radiometer for the Earth Observing System (AMSR-E) [7], the Soil Moisture and Ocean Salinity missions (SMOS) [8,9], and the Soil Moisture Active and Passive (SMAP) missions [10]. However, it is worth mentioning that the coarse spatial resolution of the microwave soil moisture products (mostly in the range of $25-40 \mathrm{~km}$ ) limits their application in local areas, especially in the field of precision irrigation and agricultural drought assessment. Optical remote-sensing methods are also essential for soil moisture estimation because of their higher spatial resolutions. The spectral regions used by the optical methods cover the thermal infrared and visible and near-infrared (VNIR) bands. Examples of such optical methods include: (i) Physically-based or empirical radiative transfer model [11,12]; (ii) Empirical indices model of soil moisture [13,14]; (iii) Hyperspectral-based models [15]; (iv) Triangular or trapezoidal method of two-dimensional space $[16,17]$. The optical methods are easy to operate and the computational complexity is low. From the perspective of practical application, the microwave remote-sensing method is applicable to the global scale, the VNIR-thermal method is suitable for watershed, and the soil moisture index model is more effective on the regional or field scales. With the development of machine learning, statistical models combining hyperspectral data for soil moisture retrieval have emerged in recent years [18,19], such as support vector machine (SVM) [20,21], artificial neural networks (ANNs) [22,23], etc. However, these statistical models have certain limitations in explaining the variation of reflectance in terms of the spectral mechanism.

The interaction of radiation with soil (scattering, absorption, refraction, and reflection) depends on the optical properties of media, which are strongly related to the moisture content, organic carbon, metal oxide, etc. [24,25]. Modeling the processes of interaction can give useful information about surface properties [26,27]. In the optical domain $(400-2500 \mathrm{~nm})$, radiative transfer equation (RTE) is an important tool for retrieving information about soils. It can explicitly relate bidirectional reflectance to the optical properties of soil such as the single scattering reflectance (SSA), absorption and backscattering coefficients, porosity factor and scattering phase function $[28,29]$. Although various SMC estimation methods have their advantages, they are often empirical. Comparatively, physical models or semi-empirical models based on the RTE are more complicated than statistical methods, but provide a more general approach to analyzing different samples. To date, some research has demonstrated the retrieval method of SMC based on the RTE physical process. Bach and Mauser [30] ascribed the general darkening of soil to the internal reflection of incident radiation in the soil water layer, and the water-specific absorption phenomena were formulated by the Beer-Lambert-Bouguer law. Sadeghi et al. [31] presented a physically-based soil moisture retrieval model in the solar domain that was based on the Kubelka-Munk two-flux radiative transfer theory. Roosjen et al. [32] studied the effects of SMC on anisotropic reflectance with the Rahman-Pinty-Verstraete (RPV) model, and the results indicated that reflectance anisotropy contains more information on SMC than spectral reflectance. Bablet et al. [11] derived a semi-empirical multilayer radiative transfer model of soil reflectance (MARMIT), considering the multiple reflection and refraction processes between air, water, and soil. Yuan et al. [12] deduced the relationship between SMC and diffuse reflectance using the absorption coefficient and scattering coefficient related to SMC, and proposed the SMC retrieval model based on the Kubelka-Munk theory. The main SMC retrieval models based on a physical process are summarized in Table 1, which also lists the corresponding expressions and the meanings of the parameters. The physical methods often require prior information that is difficult to determine, and their application is limited due to a lack of explicit equations that relate the bidirectional reflectance parameters to soil properties. 
The Hapke photometric model [33] is the most widely used kind of Bidirectional Reflectance Distribution Function (BRDF) model in the soil remote sensing research. However, the Hapke model does not consider soil moisture, which limits its application in soil moisture inversions using remote sensing data. Yang et al. [34] extended the SOILSPECT model [35] with the soil equivalent water thickness to establish the SWAP-Hapke soil directional radiation model. The SWAP-Hapke model is based on multi-angle data, while the valid spaceborne multi-angular data set is not much. The major contributions of this study are as follows: (i) proposed and evaluated a novel soil moisture retrieval model based on Hapke model (SMR-Hapke model), which can be applied to single-angular reflectance data. The model contains five physical and empirical parameters to determine the conversion between moisture content and reflectance; (ii) developed a new normalized difference soil moisture index $\left(N D S M I_{\text {Hapke }}\right)$ from the linearized SMR-Hapke model in the shortwave infrared (SWIR) region, and compared the performance with other moisture index models; (iii) high-resolution SMC map was produced combining the Sentinel-2 MSI multispectral data and NDSMI Hapke .

Table 1. Summary of the SMC retrieval models based on physical processes.

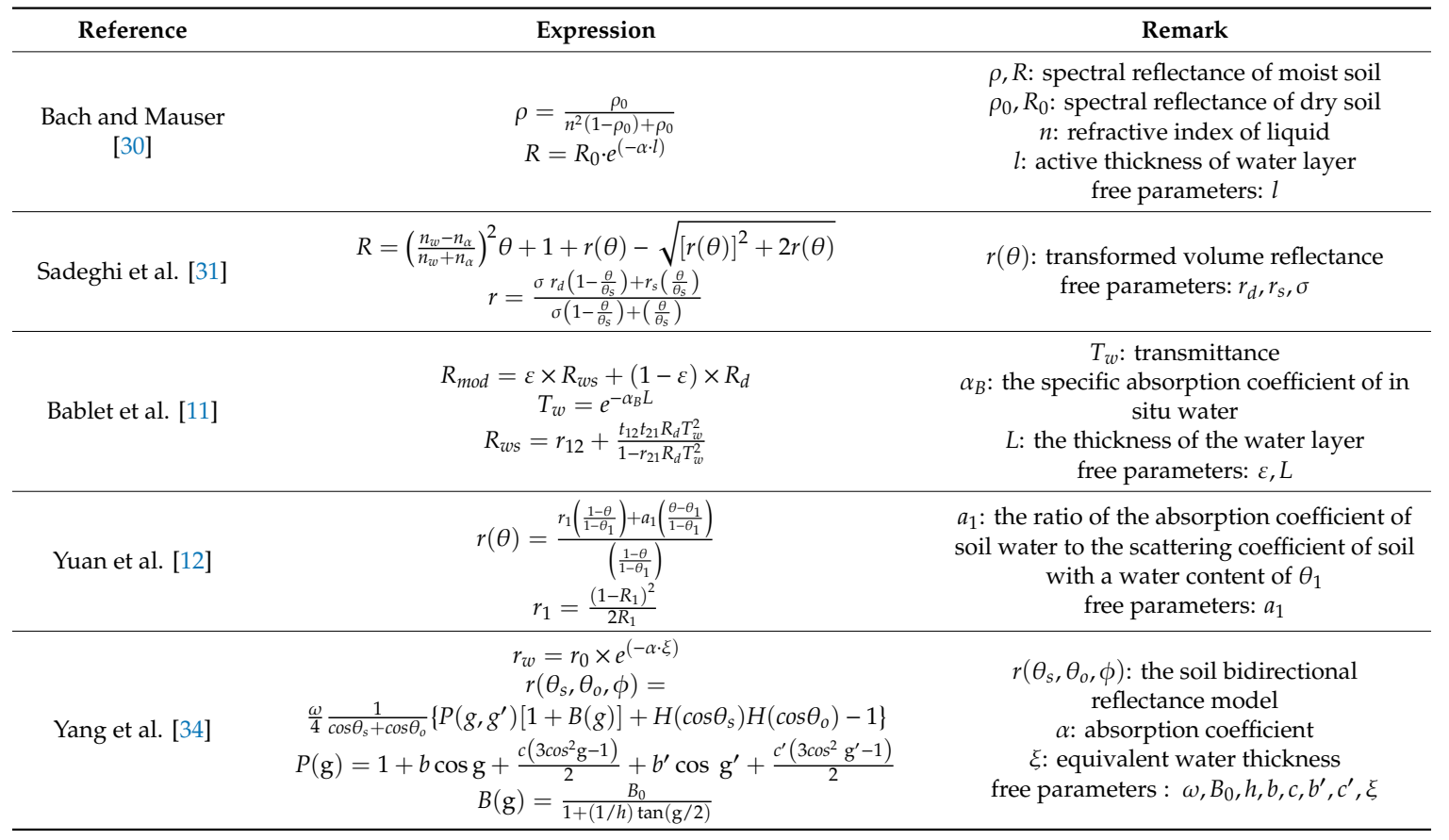

\section{Background and Methods}

\subsection{Description of SMR-Hapke Model}

The formulation of the radiative transfer theory derived by Hapke [36] describes the interaction of light with a medium, and taking the physical, geometry, and optical parameters of the particles into account. It is the most widely used photometric model in planetary astronomy, earth observation research and mineralogical information estimation [37,38], and this model is simple and can reproduce the photometric response of bare surfaces well [39]. In the Hapke model, the bidirectional reflectance $r\left(\mu_{0}, \mu\right)$ can be derived using Equation (1):

$$
r\left(\mu_{0}, \mu\right)=\frac{\omega}{4} \frac{1}{\mu_{0}+\mu}\left\{P(\mathrm{~g})[1+B(\mathrm{~g})]+H\left(\mu_{0}\right) H(\mu)-1\right\},
$$

where $\omega$ is the single scattering albedo (SSA) of soil medium; $\mu_{0}$ and $\mu$ are the cosines of the incidence zenith angles and emittance zenith angles, respectively; $g$ is the phase angle and $B(\mathrm{~g})$ is 
the backscattering function. The phase function $P(\mathrm{~g})$ describes the angular distribution of the light scattered from a soil surface. The $H(x)$ function is Chandrasekhar's isotropic scattering function:

$$
H(x)=\frac{1+2 x}{1+2 x \sqrt{1-\omega}} .
$$

For dense mixed media, the incident light will usually interact with the particles of the mixture many times before reaching the sensor. The parameter $\omega$ is defined as the probability that the photons would be scattered by the particle:

$$
\omega=\frac{S}{E}=\frac{S}{S+A},
$$

where $S$ and $A$ are the average scattering coefficient and average absorption coefficient of the medium, respectively; $E$ is the average extinction coefficient of the medium, equal to $S+A$. It can be reasonably assumed that the $S$ and $A$ values are the summed function of the absorption and scattering coefficients of its components [31,40]. Considering the effect of moisture content, $S$ and $A$ can be expressed as follows:

$$
\begin{gathered}
A=A_{d}+A_{w} \theta, \\
S=S_{d}+S_{w} \theta .
\end{gathered}
$$

where $A_{d}$ and $A_{w}$ denote the absorption coefficients of dry soil and soil moisture, respectively; $S_{d}$ and $S_{w}$ represent the scattering coefficients of dry soil and soil moisture, respectively; and $\theta$ is the volumetric moisture content (VMC), which can be calculated by Equation (5):

$$
\theta=\frac{\left(m-m_{0}\right) / \rho_{\text {water }}}{m_{0} / \rho_{b}}
$$

where $m$ and $m_{0}$ are the mass of wet and dry soil, respectively; $\rho_{b}$ represents the bulk density of soil; and $\rho_{\text {water }}$ is the density of water $\left(1.0 \mathrm{~g} \cdot \mathrm{cm}^{-3}\right)$. With the increase in the $\theta$, the absorption and scattering coefficients of saturated soil can be formulated as:

$$
\begin{gathered}
A_{s}=A_{d}+A_{w} \theta_{s}, \\
S_{s}=S_{d}+S_{w} \theta_{s} .
\end{gathered}
$$

where $\theta_{S}$ indicates the saturated moisture content. $F$ denotes equal to the ratio $A / S$, combining Equations (3) to (6) yields:

$$
F=\frac{1-\omega}{\omega}=\frac{A}{S}=\frac{A_{s}-A_{w}\left(\theta_{s}-\theta\right)}{S_{s}-S_{w}\left(\theta_{s}-\theta\right)} .
$$

Equation (7) reflects the relationship between SSA and SMC. However, Equation (1) is relatively complex and requires more input parameters, so it is difficult to calculate the value of SSA directly. Hapke simplified Equation (1) by making the following assumption [41]: (1) the opposition effect can be ignored when the phase angle is large enough, and $B(\mathrm{~g})=0$; (2) with the assumption of isotropic scattering properties, $\mathrm{P}(\mathrm{g})=1$. Then the analytic solution for the SSA can be calculated from $r\left(\mu_{0}, \mu\right)$ :

$$
\begin{gathered}
\omega\left(r\left(\mu_{0}, \mu\right)\right)=1-\left[\frac{\sqrt{\left(u_{0}+u\right)^{2}-\left(4 u_{0} u+\Gamma\right)(1-\Gamma)}-\left(u_{0}+u\right)}{4 u_{0} u+\Gamma}\right]^{2}, \\
\Gamma=\frac{\left(1+2 u_{0}\right)(1+2 u)}{4\left(u_{0}+u\right) r\left(\mu_{0}, \mu\right)} .
\end{gathered}
$$

In cases of high moisture content, especially near saturation or oversaturation, the influence of Fresnel reflection, which is typically only a small fraction of the total reflectance, needs to be considered. The optical properties of soil moisture are difficult to determine due to the suspended particles and 
dissolved organic matter. Therefore, in order to simplify the modeling process, the reflectance of pure water is used to represent Fresnel reflection $R_{F}$ :

$$
R_{F}=\left(\frac{n_{w}-1}{n_{w}+1}\right)^{2},
$$

where $n_{w}$ represents the refractivity of pure water. The calculated spectral reflectance of pure water is shown in Figure 1 using the measurements of Segelstein [42].

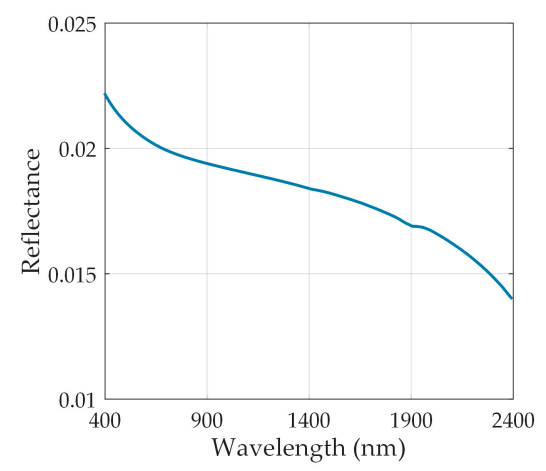

Figure 1. Spectral reflectance of pure water [42].

Then a total reflectance $\left(R_{t}\right)$ model of wet soil is established by adding the Fresnel reflectance to the volume bidirectional reflectance from the Hapke model:

$$
R_{t}=\varepsilon \cdot R_{F}+r\left(\mu_{0}, \mu\right)=\varepsilon\left(\frac{n_{w}-1}{n_{w}+1}\right)^{2}+\frac{\omega}{4} \frac{1}{\mu_{0}+\mu} H\left(\mu_{0}\right) H(\mu),
$$

subject to:

$$
\begin{gathered}
\omega=\frac{1}{1+F}, \\
F=\frac{r_{s}-t_{1}\left(\theta_{s}-\theta\right)}{1-t_{2}\left(\theta_{s}-\theta\right)},
\end{gathered}
$$

with $r_{s}=A_{s} / S_{s}, t_{1}=A_{w} / S_{s}$, and $t_{2}=S_{w} / S_{s}$. The $\varepsilon$ parameter is utilized to adjusting the surface effect of the soil moisture. In order to facilitate the practical application in remote sensing, Equations (11)-(13) are further rearranged so that SMC can be directly calculated according to $R_{t}$ :

$$
\begin{gathered}
\theta=\theta_{s}-\frac{F-r_{s}}{F t_{2}-t_{1}}, \\
F=\frac{1-\omega\left(R_{t}-\varepsilon R_{F}\right)}{\omega\left(R_{t}-\varepsilon R_{F}\right)} .
\end{gathered}
$$

The $\omega(x)$ function is calculated by Equations (8) and (9). Five parameters $\left(\varepsilon, r_{s}, t_{1}, t_{2}\right.$, and $\left.\theta_{s}\right)$ were introduced into the soil moisture retrieval model, which renamed the SMR-Hapke model. $\theta_{s}$ represents the saturated moisture content of the soil, which is independent of the wavelength. $\varepsilon$ controls the proportion of Fresnel reflection by the water film on the soil surface. $r_{s}, t_{1}$ and $t_{2}$ are the functions of the surface roughness, observation geometry, and refractive index, which are closely related to the absorption and scattering characteristics of the soil and are difficult to obtain by direct measurement. If the corresponding parameter values of each sample at different wavelengths are calculated, the mutual conversion of $R_{t}$ and $\theta$ can be realized. The variables and their definitions of SMR-Hapke model are summarized in Table 2. 
Table 2. Description of the parameters of SMR-Hapke model.

\begin{tabular}{|c|c|}
\hline Symbol & Description \\
\hline$R_{t}$ & The total reflectance received from sensor. \\
\hline$R_{F}$ & $\begin{array}{l}\text { Fresnel reflection at the air-soil interface due to differences in the refractive indices of the } \\
\text { soil and surrounding air. }\end{array}$ \\
\hline$\mu_{0}, \mu$ & The cosines of incidence zenith angles and emittance zenith angles. \\
\hline$r\left(\mu_{0}, \mu\right)$ & The bidirectional reflectance from the Hapke model. \\
\hline$n_{w}$ & The refractivity of pure water. \\
\hline$\varepsilon$ & The parameter to adjusting the surface effect of the soil moisture. \\
\hline$\omega$ & $\begin{array}{l}\text { Single scattering albedo (SSA), which is defined as the ratio of the amount of light scattered } \\
\text { from the medium to the combined amount of light scattered and absorbed at a } \\
\text { given wavelength. }\end{array}$ \\
\hline$H(x)$ & The approximation of Chandrasekhar's isotropic scattering function. \\
\hline$S, A$ & The average scattering coefficient and average absorption coefficient of the medium. \\
\hline$F$ & The ratio of absorption coefficients to scattering coefficient. \\
\hline
\end{tabular}

\subsection{NDSMI Hapke: Normalized Difference Soil Moisture Index Based on the Hapke Model}

Since the optical properties of soil depend on the physical and chemical properties of the components, the parameters in the proposed Equation (11) should also vary greatly with the heterogeneity of the soil, and the nonlinear form of SMR-Hapke model increases the complexity of inversion. It should be noted that the scattering effect of soil moisture is much weaker than that of soil particles in the Shortwave Infrared (SWIR) field (especially on the sensitive bands of moisture), so we assumed that the effects of $t_{2}$ were inconsequential and could be ignored. With this consideration, Equation (14) can be reformulated as:

$$
\theta=\frac{F}{t_{1}}+\frac{t_{1} \theta_{s}-r_{s}}{t_{1}}
$$

Equation (16) reflects the linear relationship between $\theta(\mathrm{SMC})$ and $F$. In the practical application using satellite remote sensing, under the assumption that Fresnel reflection is negligible, $F$ can be calculated from bidirectional reflectance according to Equations (7)-(9) and the moisture content can be obtained by simple linear regression method with Equation (16).

The sensitive bands of soil moisture retrieval in laboratory spectrometry are near 1450 and $1900 \mathrm{~nm}$, which are shown in Figure 2. However, these bands are usually not used in satellite remote sensing imagery due to the strong interference of atmospheric water-vapor. The European Space Agency launched Sentinel-2, which carries an innovative wide-swath, high-resolution, multispectral imager (MSI) with 13 spectral bands covering the visible, near-infrared (VNIR) and the shortwave-infrared (SWIR) spectral region. Spectral band $11(1610 \mathrm{~nm})$ and band $12(2190 \mathrm{~nm})$ are less affected by water vapor absorption and present a well sensitivity with the fluctuations of moisture, which have greater potential to be applied for the SMC estimation. Therefore, these two bands were utilized to establish the soil moisture index model. 


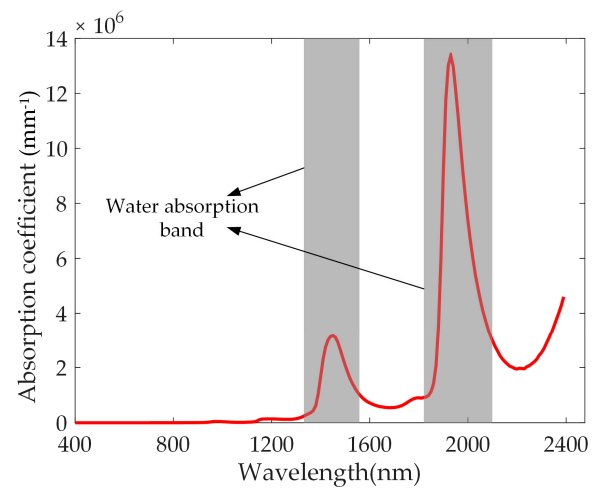

Figure 2. Absorption coefficient of pure water $[43,44]$.

Single-band SMC retrieval with traditional broadband remote-sensing data may cause the lower performance. While the combination of different bands can reduce the effects of soil type and instrumental errors. Figure $3 \mathrm{a}, \mathrm{b}$ illustrate the soil reflectance and the corresponding $F$ calculated by Equations (7) to (9), respectively. The difference value $\left(F_{2190}-F_{1610}\right)$ indicates a significant linear relationship with SMC (Figure 3d).
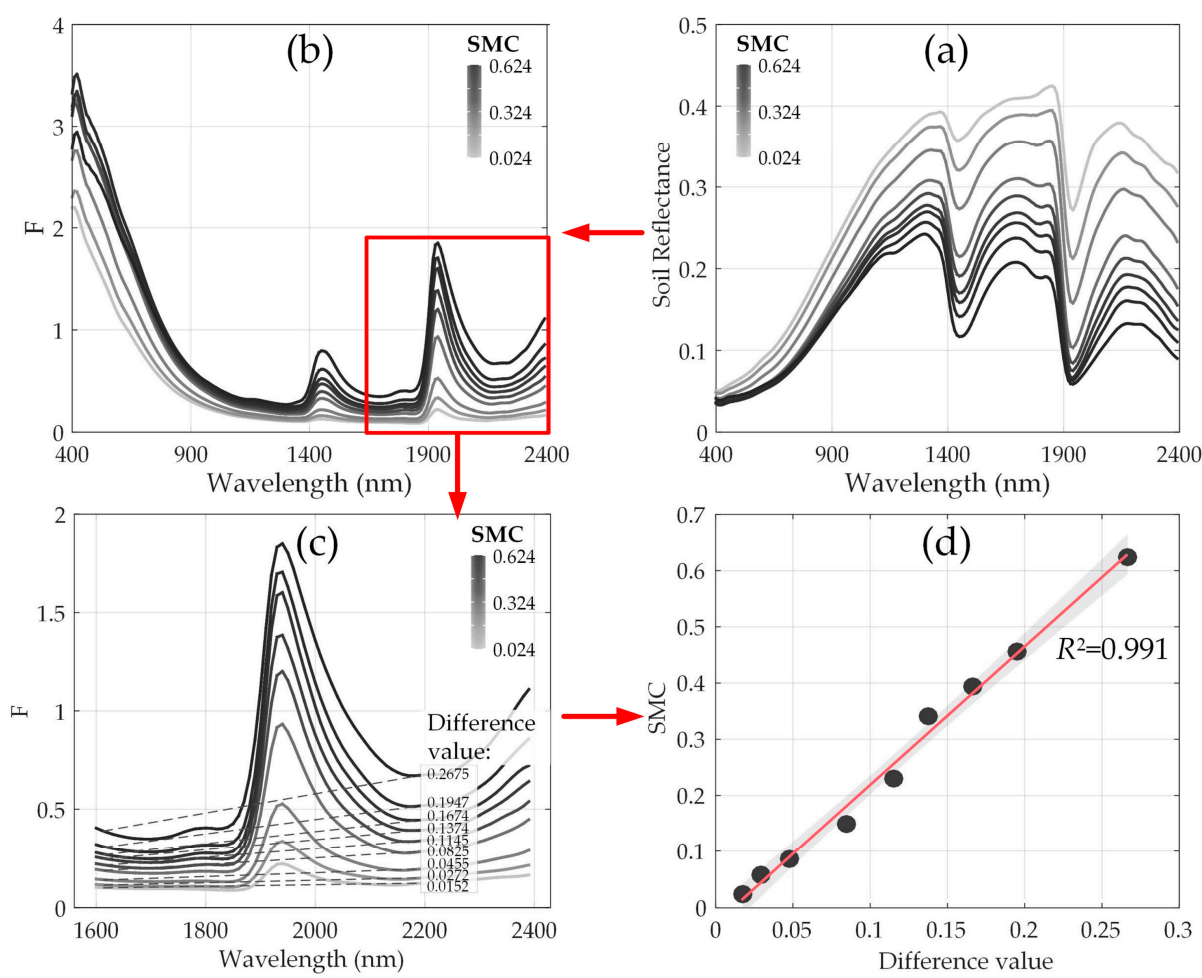

Figure 3. (a) Reflectance of Mollisol soil; (b) F value of Mollisol soil calculated by Equations (7) to (9); (c) Value of $F_{2190}-F_{1610}$; (d) Difference value and SMC.

Considering the correlation between SMC and the difference of $F$ on two shortwave-infrared bands, a normalized difference soil moisture index based on the Hapke model was developed:

$$
\mathrm{NDSMI}_{\text {Hapke }}=\frac{F_{2190}-F_{1610}}{F_{2190}+F_{1610}} .
$$

where $F_{2190}$ and $F_{1610}$ represent the value of $F$ at $2190 \mathrm{~nm}$ and $1610 \mathrm{~nm}$ calculated from Equations (7) to (9). To date, some indices have been proposed to determine and map soil moisture. Five indices are listed in Table 3, which are mainly calculated by the reflectance of the SWIR bands. 
Table 3. Soil moisture indices found in the literature.

\begin{tabular}{ccc}
\hline Soil Moisture Index & Equation & Reference \\
\hline NSMI & $\left(B_{1800}-B_{2119}\right) /\left(B_{1800}+B_{2119}\right)$ & Haubrock et al. [4] \\
NINSOL & $\left(B_{2076}-B_{2230}\right) /\left(B_{2076}+B_{2230}\right)$ & Fabre et al. [14] \\
NINSON & $\left(B_{2122}-B_{2230}\right) /\left(B_{2122}+B_{2230}\right)$ & OltraCarrió et al. [45] \\
STR & $\left(1-B_{2185}\right)^{2} / 2 B_{2185}$ & Sadeghi et al. [46] \\
NSDSI1 & $\left(B_{1694}-B_{2230}\right) / B_{1694}$ & Yue et al. [13] \\
\hline
\end{tabular}

\section{Research Area and Data}

\subsection{Data Preparation for SMR-Hapke Model}

In this section, the accuracy of the proposed SMR-Hapke model was evaluated using laboratory spectral data of four soils at different SMC gradients, as shown in Table 4. Spectral data of Aridosol, Endisol and Mollisol were measured and published by Lobell [47]. The quartz sand's data are from J. Tian [48].

Table 4. Summary of the main information on the datasets.

\begin{tabular}{cccccc}
\hline \multirow{2}{*}{ Soil Type } & \multicolumn{2}{c}{ SMC } & \multicolumn{2}{c}{ Angles } & \multirow{2}{*}{$\begin{array}{c}\text { Bulk Density } \\
\mathbf{n n y y y n}\end{array}$} \\
\cline { 2 - 5 } Levels & Range & Incidence & Emittance & \\
\hline Aridosol & 10 & $0-0.319$ & $15^{\circ}$ & $0^{\circ}$ & 1.54 \\
\hline Endisol & 7 & $0-0.442$ & $15^{\circ}$ & $0^{\circ}$ & 1.35 \\
\hline Mollisol & 9 & $0-0.696$ & $15^{\circ}$ & $0^{\circ}$ & 0.64 \\
\hline Quartz sand & 9 & $0-0.354$ & - & $0^{\circ}$ & 1.44 \\
\hline
\end{tabular}

The Quartz sand's incidence zenith angle is not provided in the literature [48], and set to $15^{\circ}$ in this article. Considering the correlation of adjacent bands, the spectra were resampled at $10 \mathrm{~nm}$ intervals, and then the Savitzky-Golay method was adopted for denoising. The size of the filtering window was set to 9. The final spectral curves are depicted in Figure 4.

All soil systems are spatially heterogeneous, and soil spectra are controlled by many factors such as mineral composition, organic matter content, surface roughness, and observed geometry. Under natural conditions, the physical and chemical properties of the soil change slowly with time. In contrast, soil moisture greatly affects the optical properties of the soil. Generally speaking, moist soil has a lower reflectance than dry soil, with a varying decreasing rate in the optical bands (400-2400 $\mathrm{nm})$. It is clear that the reflection spectra of the different soil types are diverse, as shown in Figure 4. From the absorption characteristics, it can be seen that there are two strong water absorption bands near $1400 \mathrm{~nm}$ and $1900 \mathrm{~nm}$, which dominate the reflectance in the SWIR bands. As a result of the differences in soil texture, the absorption peaks of the different soils types vary in depth, width, and displacement. However, the spectral curves at different SMC levels show similar shapes, which present an approximately parallel trend. Compared with the SWIR bands, the visible bands (400-700 nm) show a lower response to the fluctuations of moisture content, with no significant change of the curve shape. 
(a) Aridosol

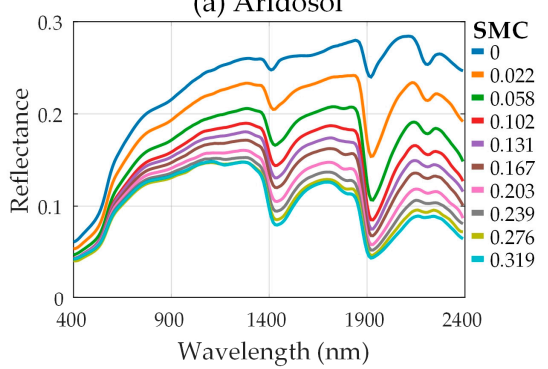

(c) Mollisol

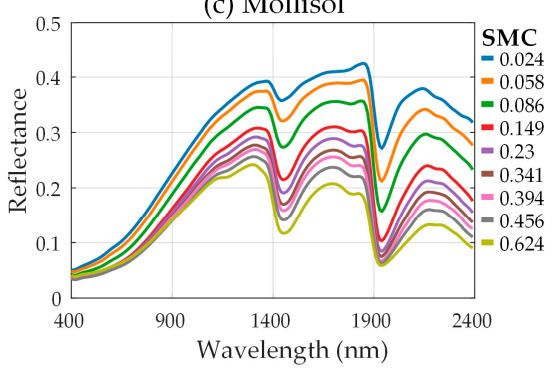

(b) Entisol

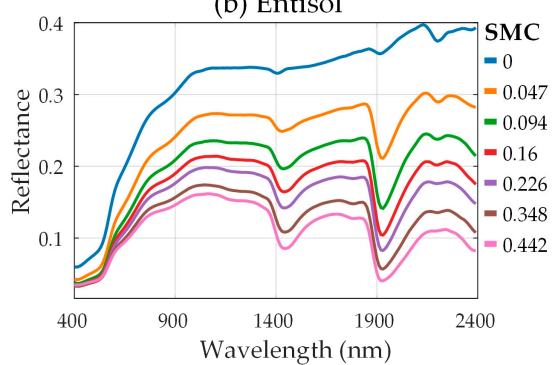

(d) Quartz sand

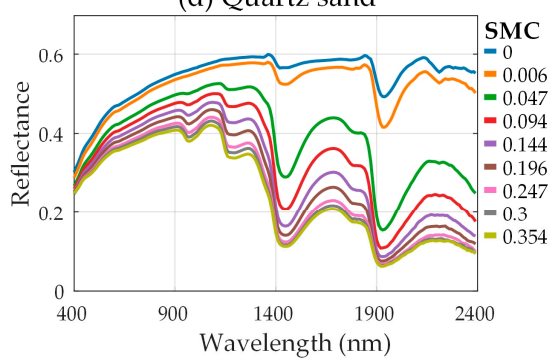

Figure 4. Spectral reflectance of the four soil samples under various levels of volumetric soil water content.

\subsection{Data Preparation for $N D S M I_{\text {Hapke }}$}

\subsubsection{Research Area and Experiments}

In order to explore the application of the proposed NDSMI Hapke model, soil samples were collected

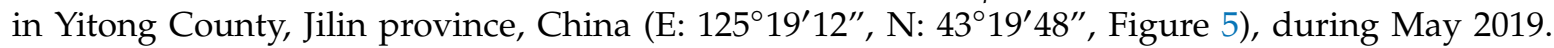
This area belongs to the humid monsoon climate zone, which is in the middle temperate zone of China. The region is hilly, with an average annual temperature of $5.5^{\circ} \mathrm{C}$. The annual average precipitation is $651.7 \mathrm{~mm}$, and the sunshine is sufficient. Yitong River runs through the whole research area from southeast to northwest. The average altitude of the study area is $305 \mathrm{~m}$, the lowest altitude is $262 \mathrm{~m}$, and the highest altitude is $446 \mathrm{~m}$. The soil types in the area are mainly dark brown forest soil, meadow soil, black soil and alluvial soil.
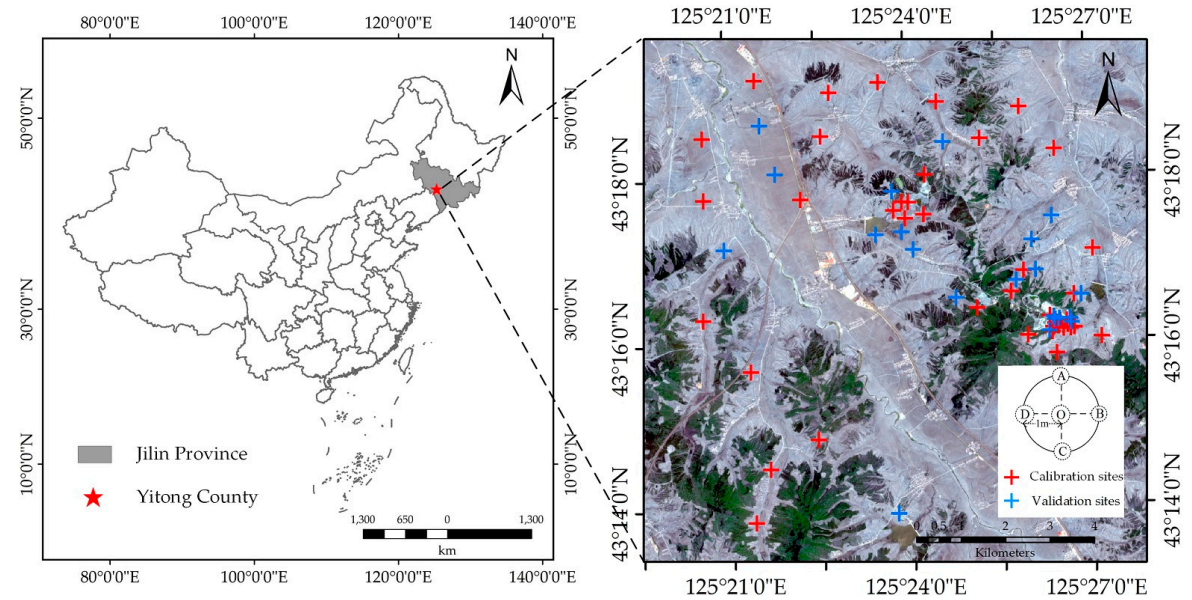

Figure 5. Location of the study area and sampling points. The red and blue points indicate the calibration and verification sites, respectively.

The farmland soil can be available due to the ploughing of the fields. The principle of soil sampling in this study is to arrange the sampling points in the farmland area as evenly as possible according to the traffic conditions. A total of 65 sites were surveyed in the study area, and three soil samples at 
different depths (1-5 cm, 20-40 cm, and 60-80 cm) for each sampling point were collected. Surface soil (1-5 cm) was collected by five-point sampling method for verification of Sentinel MSI Images. All the samples were immediately put into impermeable sealed bags, and a total of 195 samples were collected. Almost all the soil samples are characterized as clay loam, and a small amount of sandy loamy soil are present in the area (Figure 6).

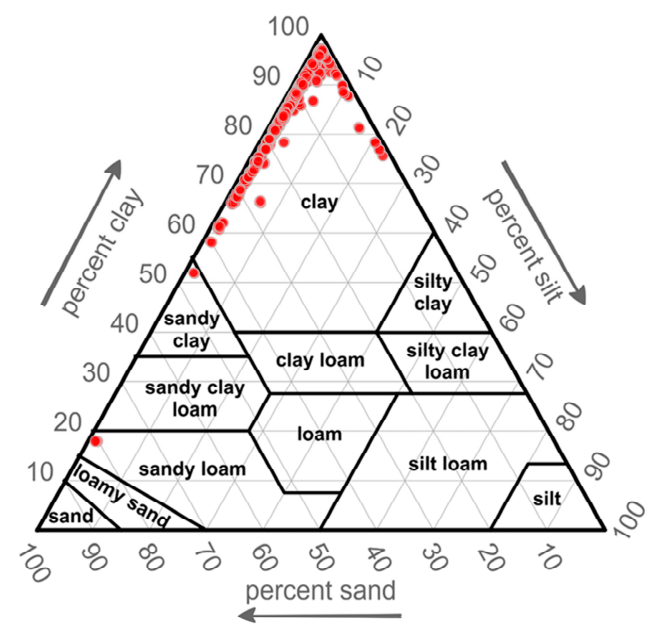

Figure 6. Texture of the studied soil samples. The size of the soil particles was divided into clay $(\leq 2 \mu \mathrm{m})$, silt $(2-50 \mu \mathrm{m})$ and sand $(50-2000 \mu \mathrm{m})$ according to the United States Department of Agriculture (USDA) classification.

\subsubsection{Laboratory Measurement of Soil Moisture and Hyperspectral Reflectance}

The hyperspectral data and SMC data were collected as follows. Firstly, the soil samples were removed from the impervious sealed bags, and each sample was divided into two parts. For one part, an ML3X soil moisture meter was used to record the volumetric moisture content of the soil. Meanwhile, the other part was evenly placed into a petri dish, and an ASD FieldSpec 3 portable spectrometer with spectral range of 350-2500 nm and sampling interval of $1 \mathrm{~nm}$ was used to measure the soil hyperspectral reflectance. As shown in Figure 7, a halogen lamp is used as the light source with the illumination zenith Angle set to $40^{\circ}$. We collected each spectrum five times, and then performed outlier elimination and splice correction, taking the average spectra as the final actual reflectance data. To prevent water evaporation from affecting the measurement results, the measurement of SMC and the collection of the spectra were performed immediately after the soil samples were removed from the sealed bags. In total, 195 sets of volumetric moisture content data and hyperspectral data were acquired.
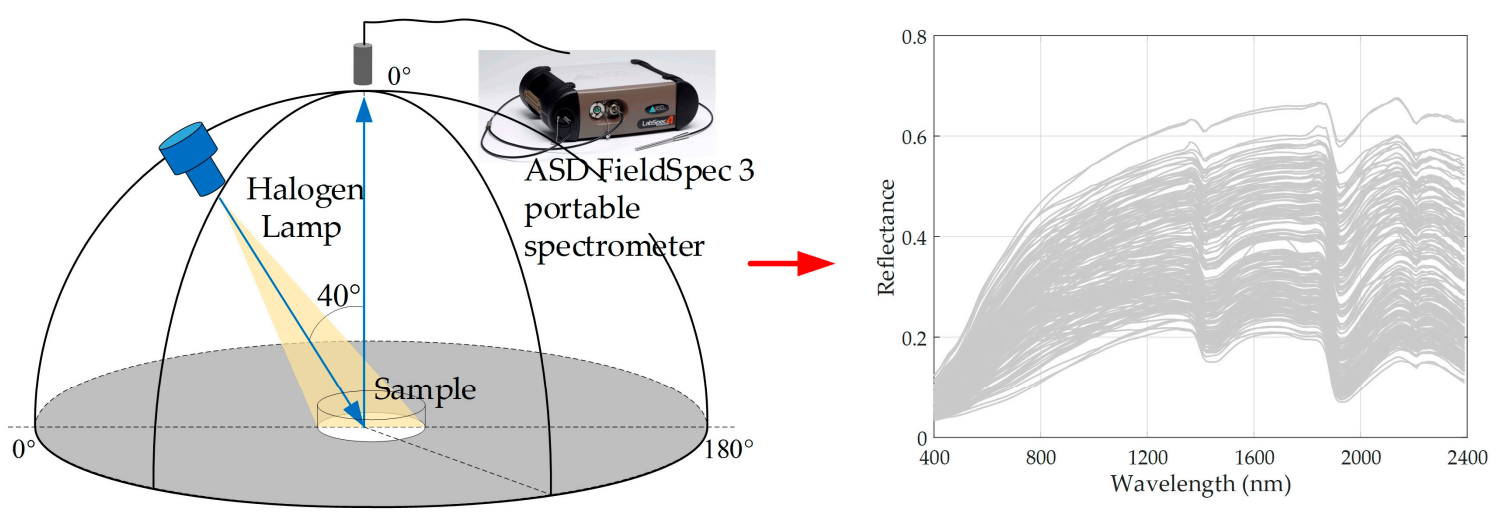

Figure 7. Experimental equipment and measured soil reflectance data. 


\subsubsection{Sentinel-2 MSI Data and Image Processing}

Sentinel-2 is an earth observation mission developed by the European Space Agency (ESA) and carries an innovative wide swath high-resolution multispectral instrument (MSI) with 13 spectral bands, covering the Vis-NIR-SWIR electromagnetic frequency domains. We acquired the Sentinel-2 MSI data from the ESA Sentinel Scientific Data Hub (https://scihub.copernicus.eu/dhus/\#/home), and the satellite transit time (2019-05-04) was two days after the field sampling (2019-05-02). Atmospheric corrections were applied to the MSI images to obtained the surface reflectance using the ESA SNAP (version 7, http://step.esa.int/main/download/snap--download/) and Sen2Cor packages (version 2.8 http://step.esa.int/main/third--party--plugins--2/sen2cor/sen2cor_v2--8/). Reflectance at the two SWIR band [band 12 (central wavelength: $2185 \mathrm{~nm}$ ) and band 11 (central wavelength: $1610 \mathrm{~nm}$ )] was utilized for the calculation of the $N D S M I_{\text {Hapke }}$, and images were resampled to 10-m resolution with the cubic convolution interpolation method. Using the Classification tools based on Support Vector Machine (SVM) in the ENVI software to extract the bare soil in the research area. Finally, the reflectance data of field sampling points of Sentinel-2 MSI images were extracted by the Geospatial Data Abstraction Library (GDAL) package. Flow charts illustrate the sequence of image-processing steps for mapping the surface soil moisture with $N D S M I_{\text {Hapke }}$ in Figure 8.
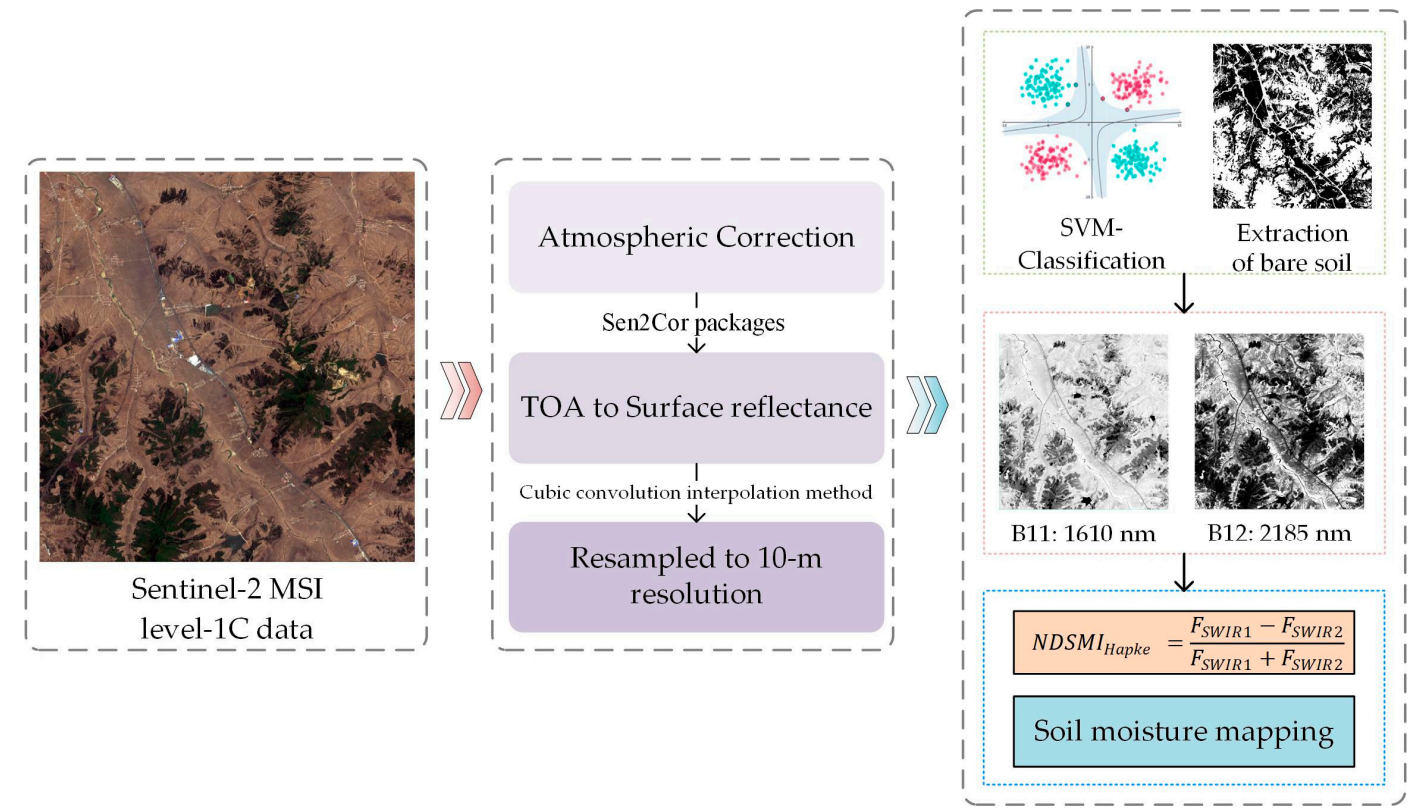

Figure 8. Flowcharts illustrating the sequence of Sentinel-2 MSI data analyses steps for mapping surface soil moisture content with $N D S M I_{\text {Hapke }}$.

\subsection{Performance Metrics}

The coefficient of determination $\left(R^{2}\right)$, root mean square error (RMSE), and mean absolute error (MAE) were used to evaluate the performance of model.

$$
\begin{gathered}
R^{2}=1-\frac{\sum_{i=1}^{N}\left(\theta_{i}^{\text {meas }}-\theta_{i}^{\text {est }}\right)^{2}}{\sum_{i=1}^{n}\left(\theta_{i}^{\text {meas }}-\overline{\theta^{\text {meas }}}\right)^{2}} \\
\text { RMSE }=\sqrt{\frac{\sum_{i=1}^{N}\left(\theta_{i}^{\text {est }}-\theta_{i}^{\text {meas }}\right)^{2}}{N}} \\
\text { MAE }=\frac{\sum_{i=1}^{N}\left|\theta_{i}^{\text {est }}-\theta_{i}^{\text {meas }}\right|}{N}
\end{gathered}
$$


where $\theta^{\text {est }}$ and $\theta^{\text {meas }}$ are the estimated and measured values of SMC, respectively; $\overline{\theta^{\text {meas }}}$ is the average measured value; and $N$ is the sample number. Mathematically, a higher $R^{2}$ value corresponds to a smaller RMSE and MAE, and represents a better modeling accuracy.

\section{Results}

\subsection{SMR-Hapke Model Application}

\subsubsection{Parameter Calculation}

Model inversion is achieved by searching the optimal values of unknown model parameters $\left(\varepsilon, r_{s}, t_{1}, t_{2}\right.$ and $\left.\theta_{s}\right)$, which minimizes the merit function. We use the mean-square error (MSE) as the merit function to measure the difference between the measured and estimated values of reflectance:

$$
\operatorname{MSE}\left(\varepsilon, r_{s}, t_{1}, t_{2}, \theta_{s}\right)=\frac{1}{N} \sum_{k=1}^{N}\left[R_{\text {true }}(\lambda)-R_{\text {pred }}\left(\lambda, \theta_{k}\right)\right]^{2}
$$

where $R_{\text {true }}(\lambda)$ is the measurement at a given wavelength $\lambda(\mathrm{nm})$, and $R_{\text {pred }}\left(\lambda, \theta_{k}\right)$ is the simulated reflectance described in Equation (11).

In this study, the optimal solutions of Equation (21) for each band are obtained by fitting the model based on the laboratory spectral data of four soils (Aridosol, Endisol, Mollisol, and Quartz sand), using the genetic algorithm of coupled nonlinear programming, implemented in Matlab R2019b. By combining the global search capability of the genetic algorithm with the local search advantage of the nonlinear programming algorithm, the merit function $\operatorname{MSE}\left(\varepsilon, r_{s}, t_{1}, t_{2}, \theta_{s}\right)$ can be minimized to obtain the global optimal solution of the inverse problem.

As an illustration, Figure 9 demonstrates that the MSE between the measured and the modeled reflectance spectra of four soils is generally lower than $3 \times 10^{-4}$ in the whole band, indicating that the proposed SMR-Hapke model shows a good performance and can accurately reflect the variation trend of soil reflectance with moisture content. The calculated optimal values are displayed in Figure 10, which reflects the variation curves of the five unknown parameters for the four samples. Figure 10 indicates that parameters $\varepsilon, r_{s}, t_{1}$ and $t_{2}$ vary greatly in range of $1200-2500 \mathrm{~nm}$, and there are obvious peaks and troughs in the two water absorption bands. Therefore, the proposed SMR-model has high sensitivity in SWIR region. Note that the value of $\theta_{s}$ barely changes in the SWIR bands, which can be ascribed to the saturated moisture content being only related to the physical and chemical properties of the soil, instead of the wavelength. The significant wave peaks of $r_{s}$ and $t_{1}$ appear near $1400 \mathrm{~nm}$ and $1900 \mathrm{~nm}$, which are due to the strong absorption of water in these spectral intervals, and result in a small scattering coefficient for the soil.

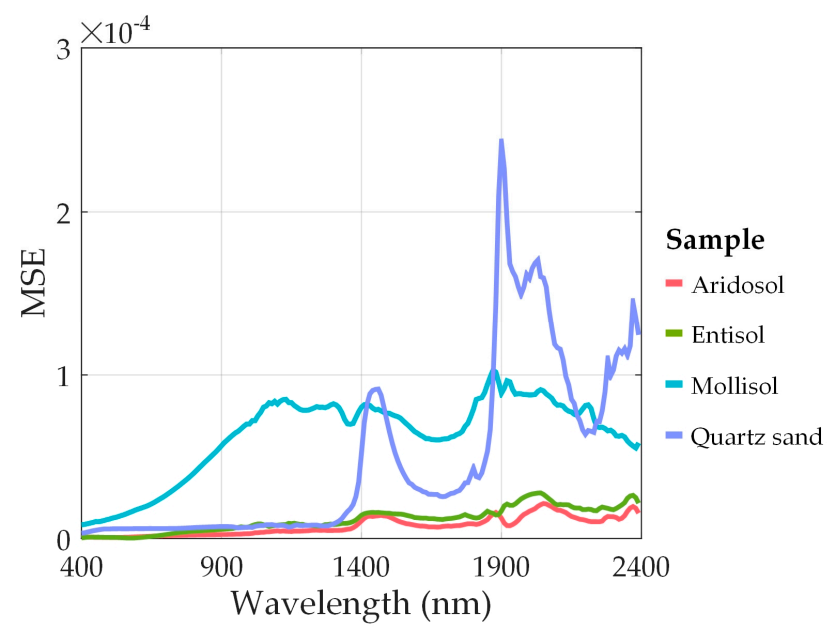

Figure 9. The $\operatorname{MSE}\left(\varepsilon, r_{s}, t_{1}, t_{2}, \theta_{s}\right)$ values of four soil samples. 

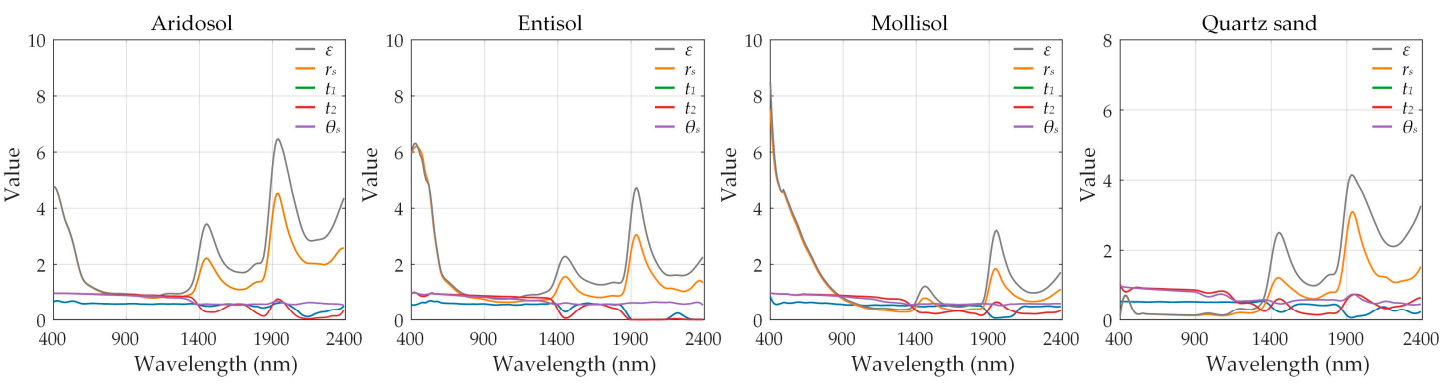

Figure 10. Parameters $\left(\varepsilon, r_{s}, t_{1}, t_{2}\right.$, and $\left.\theta_{s}\right)$ of the six soils at different wavelengths.

\subsubsection{SMC Estimation}

Using the Equations (14) to (15), the performance of the SMR-Hapke model was verified. Figure 11 shows the variation of the $R^{2}$ and RMSE values in the range of 400-2400 nm, which indicates that the proposed model has a high retrieval accuracy and stability. For the four soils, the $R^{2}$ values are generally more than 0.9 on the NIR-SWIR bands, and the RMSE values are all less than $5 \%$. The performance of the SMR-Hapke model is relatively poor in the visible region, which is due to the insensitivity of visible light to the fluctuations of SMC.
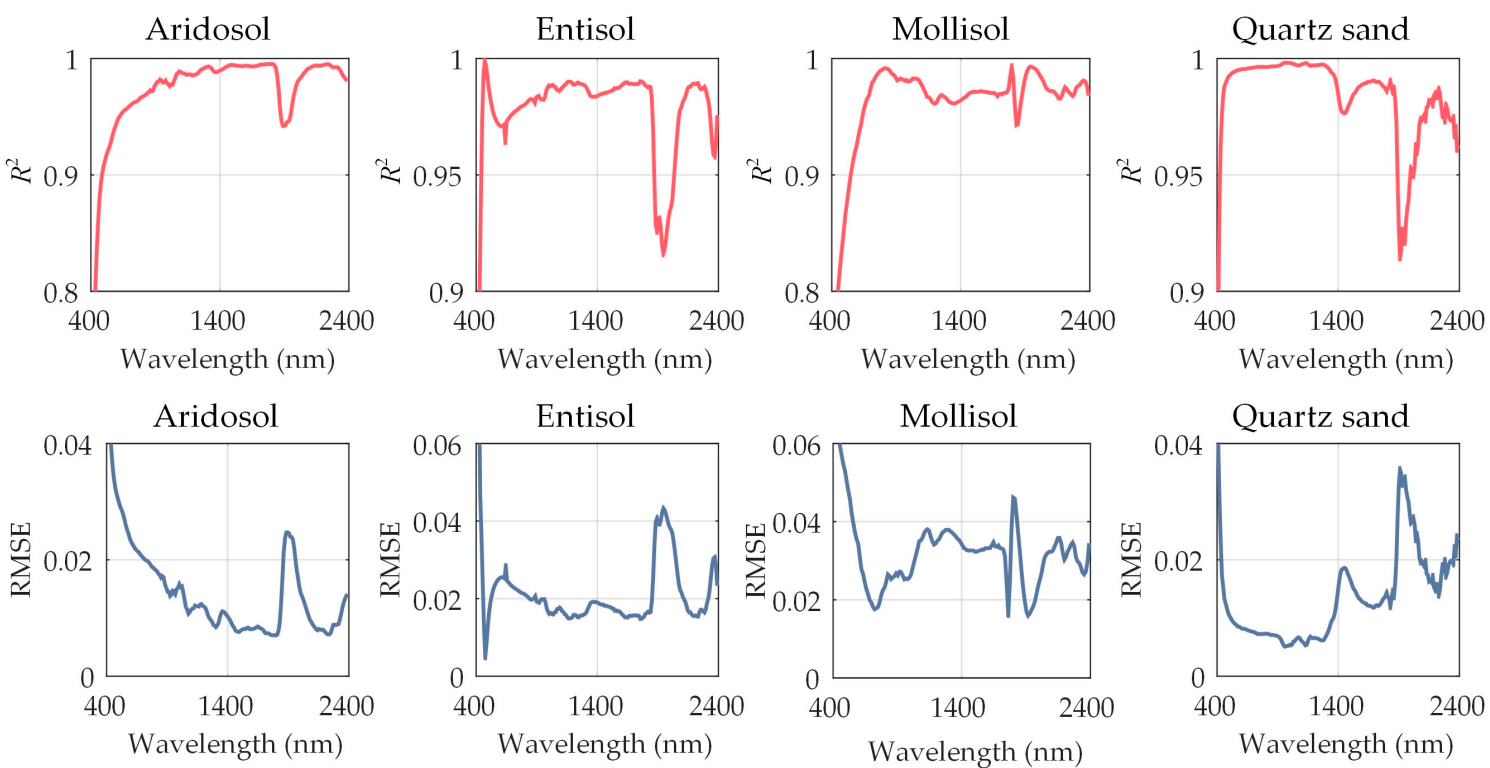

Figure 11. $R^{2}$ and RMSE at different wavelengths for four soils.

The SMC retrieval results in the whole band (400-2400 nm) are displayed in Figure 12, from which it can be clearly observed that there was a significant linear relationship between the estimated and measured SMC.
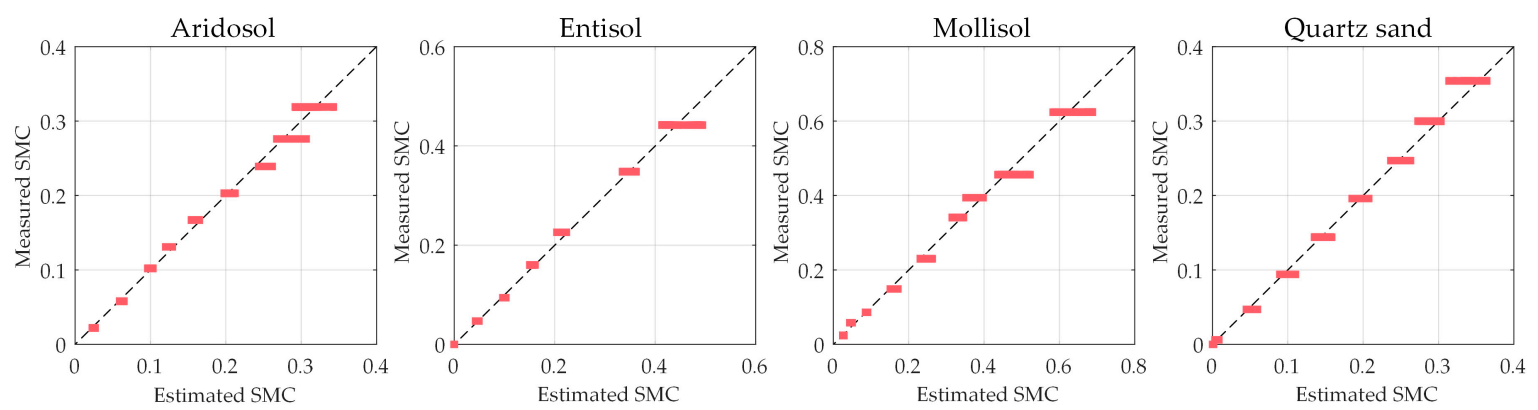

Figure 12. SMC measured and estimated using Equation (14). 


\subsection{Performance Evaluation of NDSMI Hapke}

\subsubsection{Evaluation Using Laboratory Spectral Data}

The retrieval algorithm of unknown parameters used in this study can acquire the optimal value, but each soil sample needs to measure the spectra under different moisture contents, which increases the complexity of the calculation and optimization steps. Equation (16) is a simplification of the SMR-Hapke model, in which the volumetric moisture content can be expressed as a linear function of the $F$. As an illustration, Figure 13 shows the linear relationship between $F$ and $\theta$ for the four soils on the SWIR bands (1610 nm and $2190 \mathrm{~nm}$ ), which verifies the applicability of Equation (16).
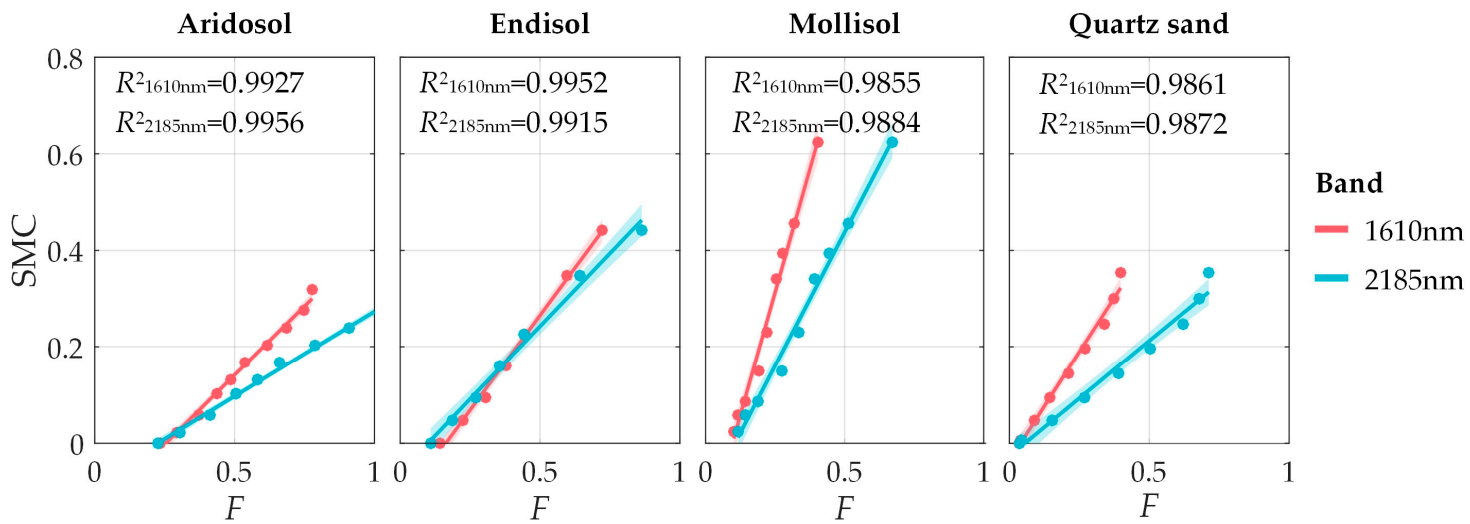

Figure 13. Relationship between SMC and $F$ of four soil in $1610 \mathrm{~nm}$ and $2185 \mathrm{~nm}$.

With field sampling and laboratory measurements, we acquired a total of 195 sets of SMC and laboratory spectral data to evaluate the performance of $N D S M I_{\text {Hapke }}$. The partition of the datasets is based on the joint $\mathrm{x}-\mathrm{y}$ distances (SPXY) method [49]. Of this total, 130 datasets were used as the calibration set to analyze the relationship between $N D S M I_{\text {Hapke }}$ and soil moisture content, and the remaining 65 datasets were used for the validation (Figure 14).

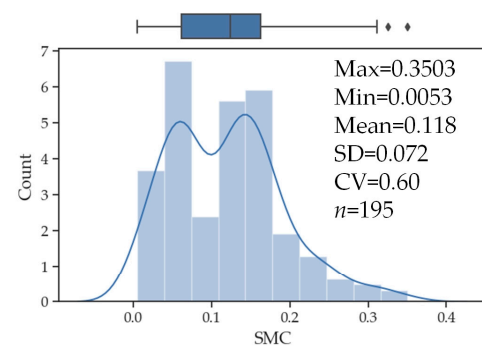

(a) Whole set

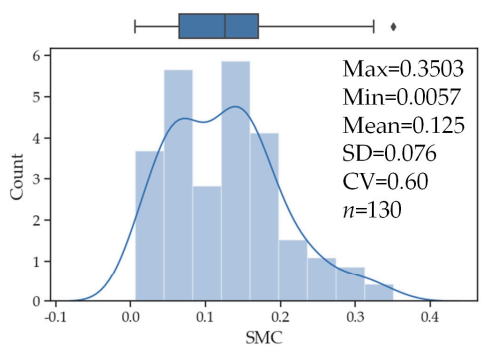

(b) Calibration set

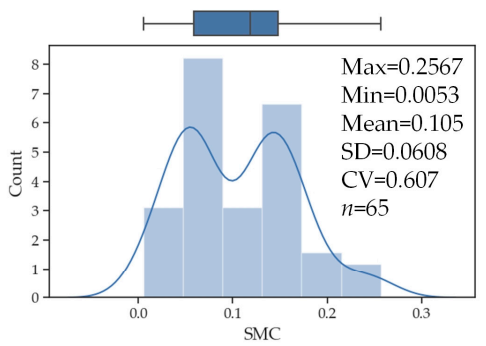

(c) Verification set

Figure 14. Box-plots, histograms, and descriptive statistics of SMC: (a) the whole set; (b) the calibration set; and (c) the verification dataset. Min: minimum, Max: maximum, SD: standard deviation, $\mathrm{CV}$ : coefficient of variation, $\mathrm{n}$ : the number of soil samples.

Based on the laboratory-based calibration dataset, we compared the accuracy of the model with other soil moisture indices by linear regression analysis. The other five soil moisture indices are listed in Table 3.

Figure 15 presents the relationships between the six indices and the SMC. The Normalized Index of NSWIR domain for SMC estimation from Linear regression (NINSOL, Figure 15b) and Normalized Index of NSWIR domain for SMC estimation from Nonlinear correlation (NINSON, Figure 15c) correlate negatively with SMC, whereas the Normalized Difference Soil Moisture Index (NSMI, Figure 15a), Soil Transformed Reflectance (STR, Figure 15d), Normalized Shortwave-infrared Difference Bare Soil Moisture Index (NSDSI1, Figure 15e), and the proposed NDSMI Hapke (Figure 15f) have a positive 
correlation with SMC. Table 5 presents the equations between SMC and the soil moisture indices. Moreover, the corresponding $R^{2}$, RMSE, and MAE values are also given. The results shown in Table 5 reflect that NSMI, NINSOL, STR, and NSDSI1 have good predication ability for SMC, with the $R^{2}$ more than 0.7. In general, with the increase in the water content, the sensitivity of each index decreases. Table 5 also indicates that the proposed $N D S M I_{\text {Hapke }}$ have great potential for estimating field SMC, with $R^{2}$ values of 0.8138 , RMSE values of 0.033 , and MAE values of 0.0263 , respectively.

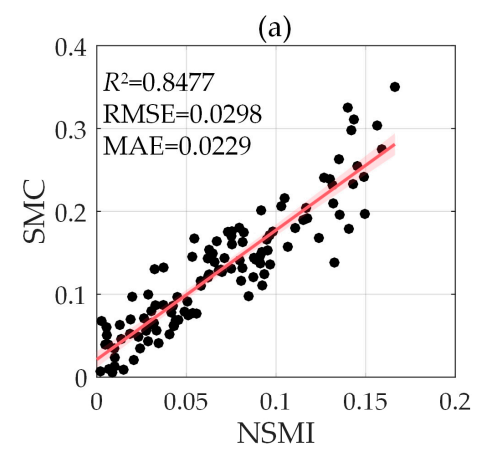

(d)

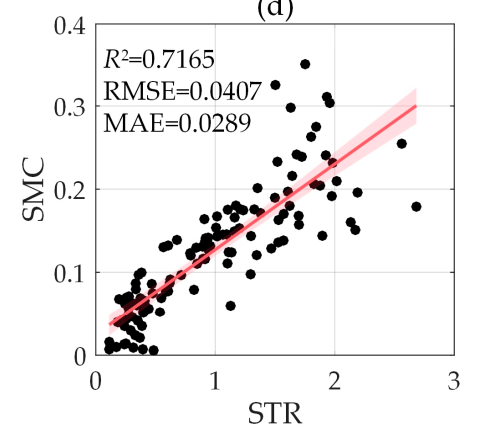

(b)

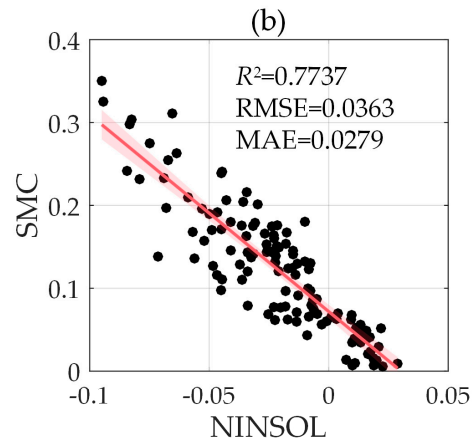

(e)

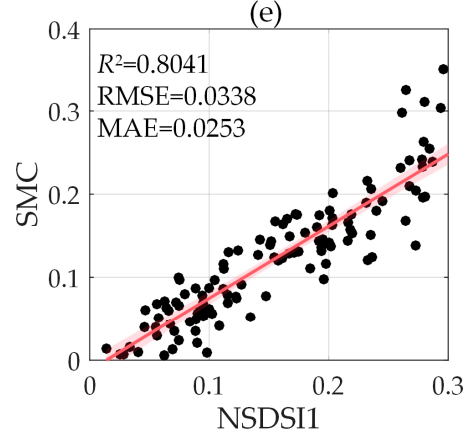

(c)

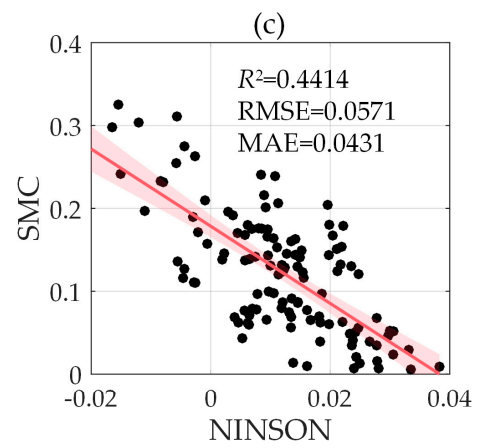

(f)

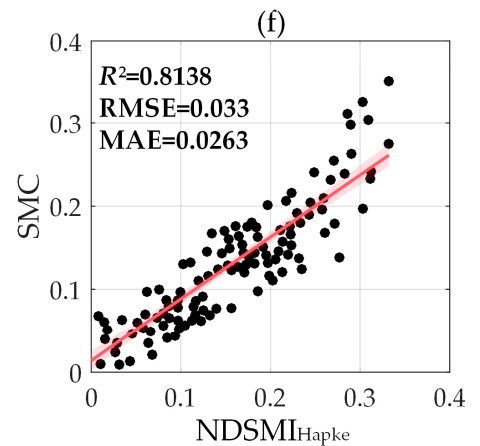

Figure 15. Linear fitting of the six moisture indices and VWC using the calibration data.

Table 5. Comparison of the SMC accuracy.

\begin{tabular}{|c|c|c|c|c|}
\hline SMC Indices & Equation & $R^{2}$ & RMSE & MAE \\
\hline NSMI & $\mathrm{SMC}=1.568 \times \mathrm{NSMI}+0.0194$ & 0.8477 & 0.0298 & 0.0229 \\
\hline NINSOL & $\mathrm{SMC}=-2.418 \times \mathrm{NINSOL}+0.0719$ & 0.7737 & 0.0363 & 0.0279 \\
\hline NINSON & $\mathrm{SMC}=-4.757 \times \mathrm{NINSON}+0.1793$ & 0.4414 & 0.0571 & 0.0431 \\
\hline STR & $\mathrm{SMC}=0.1029 \times \mathrm{STR}+0.0244$ & 0.7165 & 0.0407 & 0.0289 \\
\hline NSDSI1 & $\mathrm{SMC}=0.8714 \times \mathrm{NSDSI} 1-0.0150$ & 0.8041 & 0.0338 & 0.0253 \\
\hline NDSMI Hapke & $\mathrm{SMC}=0.7458 \times \mathrm{NDSMI}_{\text {Hapke }}+0.0138$ & 0.8138 & 0.033 & 0.0263 \\
\hline
\end{tabular}

The validation dataset was used to estimate the SMC by the linear equations listed in Table 5. Figure 16 presents the estimated and measured SMC values of the six indices and the corresponding $R^{2}$, RMSE, and MAE values. The proposed NDSMI Hapke indicated favorable performance with an $R^{2}$ of 0.8801 , an RMSE of 0.0212 , and an MAE of 0.0167 , respectively. Therefore, $N D S M I_{\text {Hapke }}$ can be used to reasonably estimate the soil moisture for regions with large spatial variability. Moreover, as a simplified single calibration equation, $N D S M I_{\text {Hapke }}$ can be obtained based on linear regression analysis with less measured data, which greatly reduces the complexity of SMC retrieval compared with the SMR-Hapke model. 

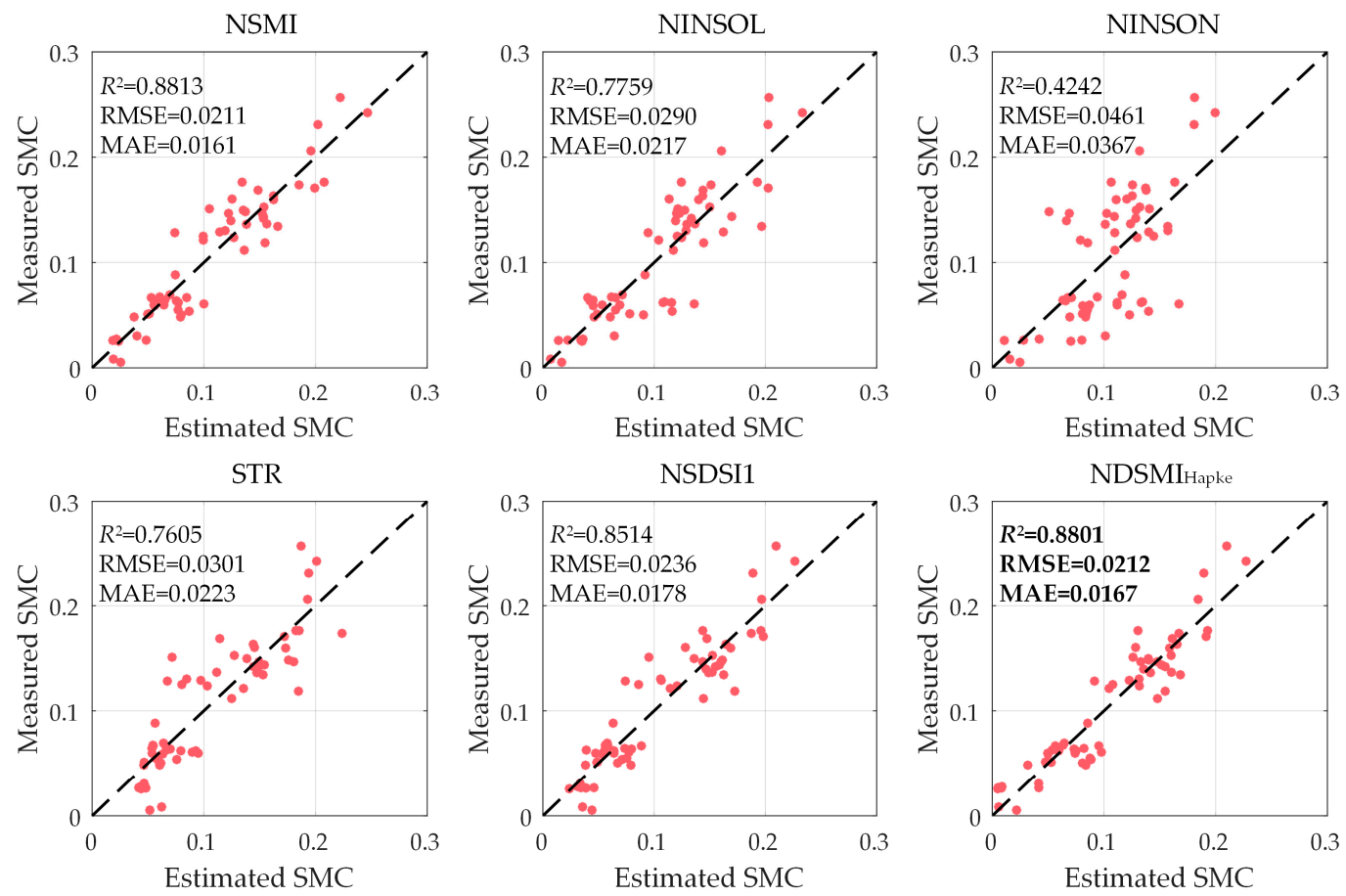

Figure 16. Estimated and measured SMC for the six soil moisture indices on the verification set.

\subsubsection{Evaluation and SMC Mapping Using Sentinel-2 MSI Data}

In order to explore the application of $N D S M I_{\text {Hapke }}$ in broadband satellite remote sensing images, the surface reflectance of the 65 field sampling points were extracted using Sentinel-2 MSI data, of which 43 sites were used as the calibration and 22 sites for the validation (Figure 5). The data are partitioned using the SPXY method. According to the remote sensing image metadata, the solar zenith angle at satellite transit time is $29^{\circ} 8^{\prime} 22.29^{\prime \prime}$. Since the image has been orthogonally rectified, the emittance angle is set to $0^{\circ}$. NDSMI Hapke was calculated by Equation (17).

Figure 17a shows a weak correlation between surface reflectance and SMC. Figure 17b,c present the SMC estimated and measured by using the $N D S M I_{\text {Hapke }}$ at calibration and validation sites. The result shows that $N D S M I_{\text {Hapke }}$ has high potential for estimating soil moisture at a regional scale, the $R^{2}$ of calibration and validation sites is generally more than 0.6. For comparison, the performance of the other two soil moisture indexes (STR and NSDSI1) were given on the SWIR Sentinel-2 bands, as shown in Figure 18. The NSMI, NINSOL and NINSON are not located in Sentinel-2 bands and therefore did not participate in the comparison.
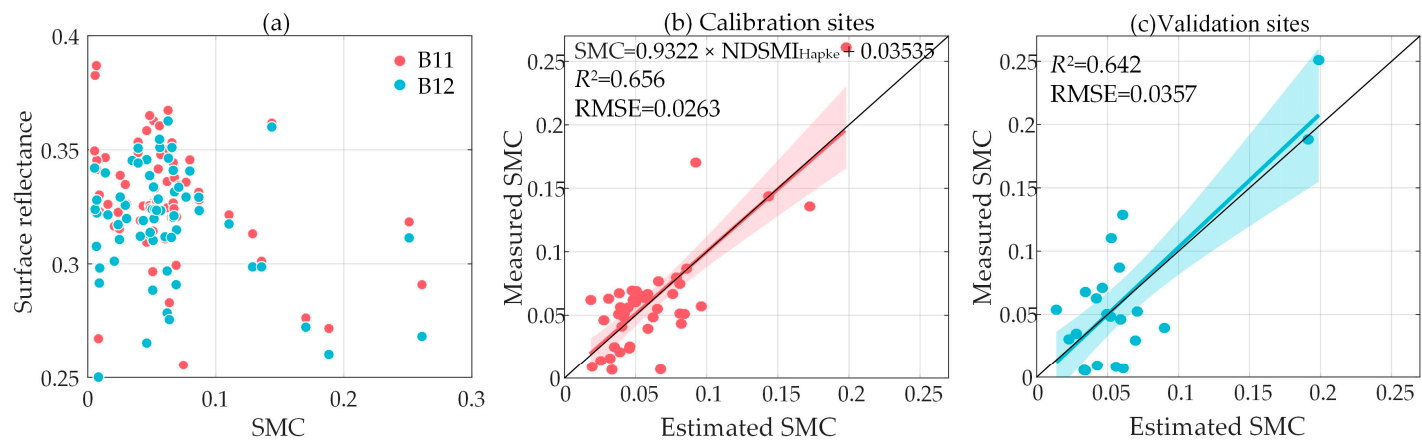

Figure 17. (a) Sentinel-2 MSI B11 (1610 nm) and B12 (2185 nm) vs SMC. (b) SMC estimated and measured by using $N D S M I_{\text {Hapke }}$ (calibration sites). (c) SMC estimated and measured by using $N D S M I_{\text {Hapke }}$ (validation sites). 
(a) STR Calibration sites

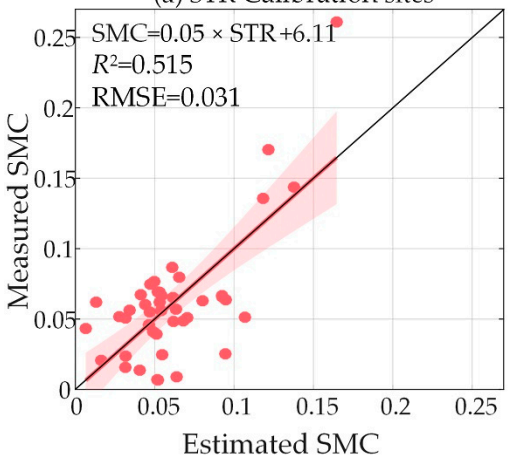

(c) NSDSI1 Calibration sites

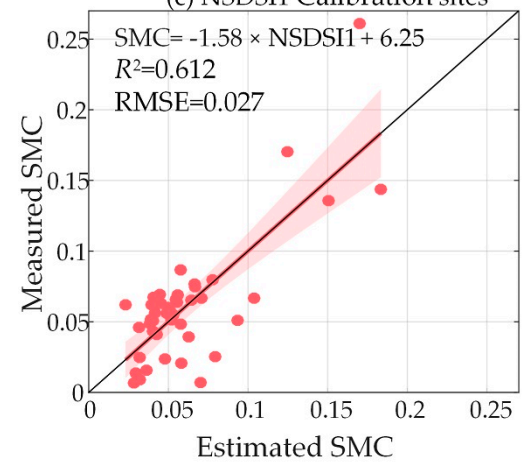

(b) STR Validation sites

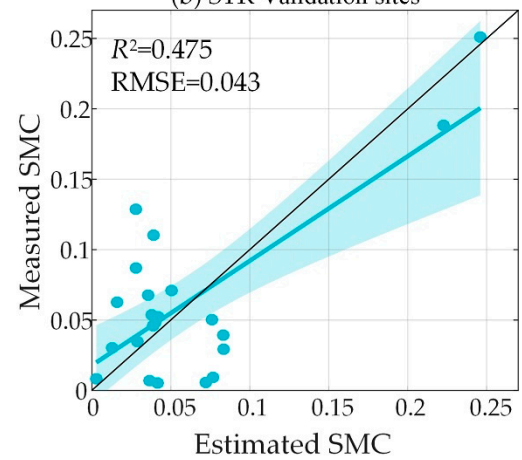

(d) NSDSI1 Validation sites

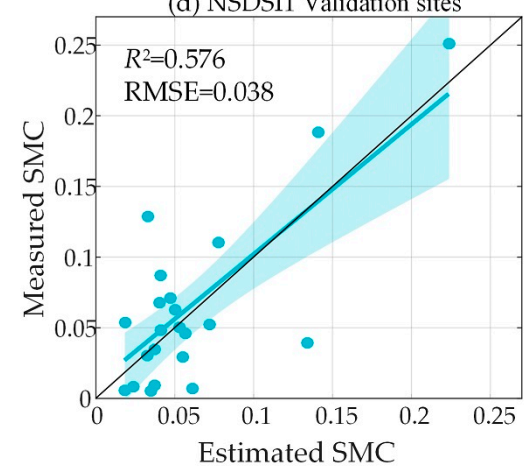

Figure 18. The SMC estimated and measured by using: (a) STR, calibration sites; (b) STR, validation sites; (c) NSDSI1, calibration sites; (d) NSDSI1, validation sites.

In Table 6, The $R^{2}$ values of STR calibration and validation are 0.515 and 0.475 , respectively. The $R^{2}$ values of NSDSI 1 calibration and validation are 0.612 and 0.576 , respectively. Table 6 indicates that the proposed $N D S M I_{\text {Hapke }}$ perform better than the other indices in estimating SMC using the broadband Sentinel-2B MSI data. As shown in Figure 19, the spatial distribution of SMC was obtained according to the linear regression equation.

Table 6. Relationship between SMC and SMC indices in broadband Sentinel-2 data.

\begin{tabular}{llllll}
\hline \multirow{2}{*}{ Indices } & \multirow{2}{*}{ Equation } & \multicolumn{2}{c}{ Calibration } & \multicolumn{2}{l}{ Validation } \\
\cline { 3 - 6 } & & $\boldsymbol{R}^{\mathbf{2}}$ & $\mathbf{R M S E}$ & $\boldsymbol{R}^{\mathbf{2}}$ & RMSE \\
\hline STR & $\mathrm{SMC}=0.05 \times \mathrm{STR}+6.11$ & 0.515 & 0.031 & 0.475 & 0.043 \\
NSDSI & $\mathrm{SMC}=-1.58 \times$ NSDSI +6.25 & 0.612 & 0.027 & 0.576 & 0.038 \\
NDSMI $_{\text {Hapke }}$ & $\mathrm{SMC}=\mathbf{0 . 9 3 2 2} \times$ NDSMI $_{\text {Hapke }}+\mathbf{0 . 0 3 5 3}$ & $\mathbf{0 . 6 5 6}$ & $\mathbf{0 . 0 2 6}$ & $\mathbf{0 . 6 4 2}$ & $\mathbf{0 . 0 3 5}$ \\
\hline
\end{tabular}




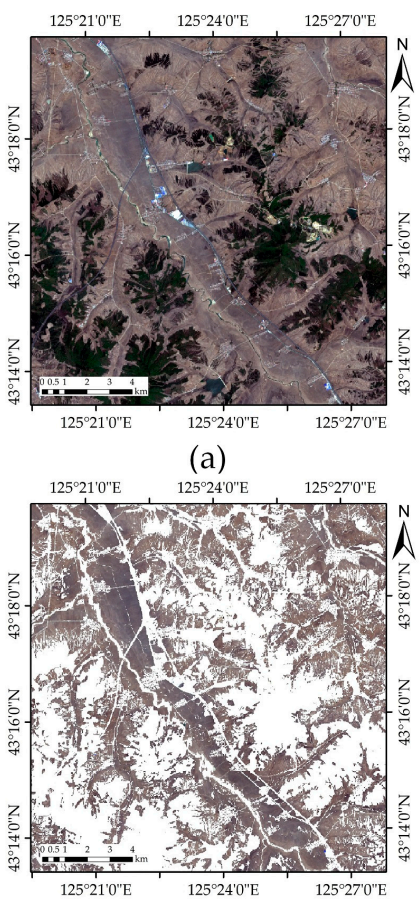

(b)

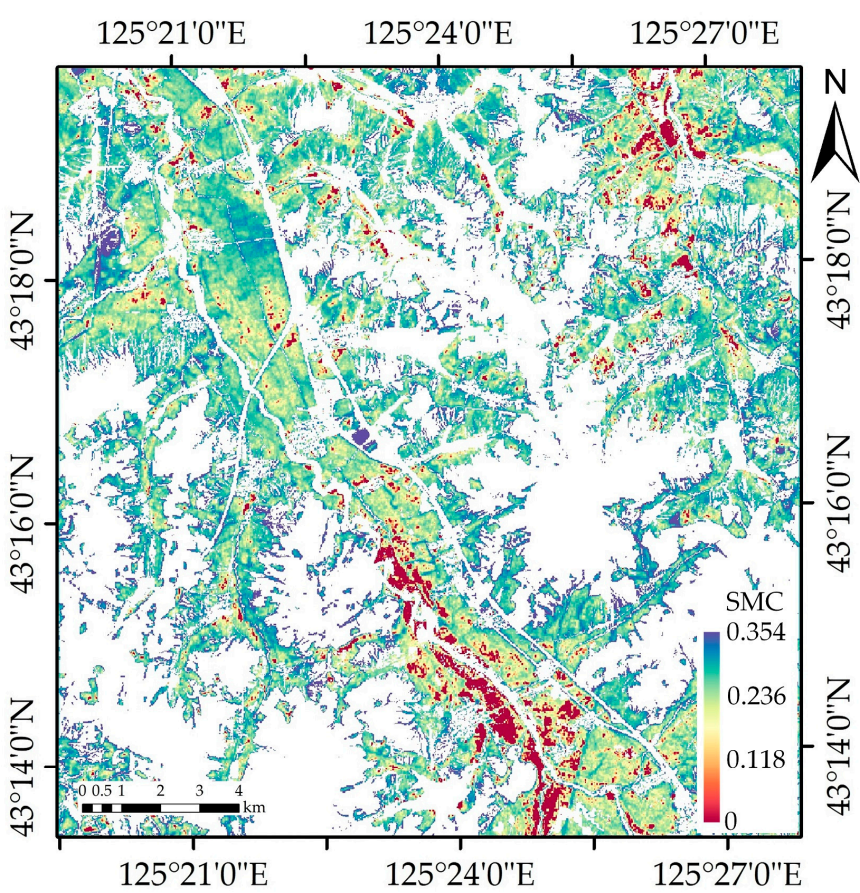

(c)

Figure 19. (a) Sentinel-2 MSI image of study area, satellite transit time: 2019-05-04; (b) Extraction of bare soil; (c) SMC map of study areas.

\section{Conclusions and Prospect}

The Hapke model is the most widely used photometric model in the scientific community and has been successfully applied to soil remote sensing research. However, multi-angle data are infrequent in the practical application of remote sensing, which is the barrier to the development of the Hapke model in SMC retrieval. In this regard, this paper built a SMR-Hapke model to investigate the relationship between single scattering albedo and soil moisture content. Moreover, a physically based normalized difference soil moisture index $N D S M I_{\text {Hapke }}$ from the SMR-Hapke model is proposed. The advantage of the proposed SMR-Hapke model is that it may be applied to any observation geometry, and is not confined to multi angle data. The genetic algorithm of coupled nonlinear programming used in this study is independent of the initial values, and can start from a random solution to find the optimal solution. The results displayed in Figures 11 and 12 indicate that the proposed model could be applied for the retrieval of SMC among different types of soils, with a high prediction accuracy in the solar domain (400-2500 nm).

To handle the spatial variation of the model parameters caused by the heterogeneity of soil, we reduced the SMR-Hapke model to a linear form and further proposed the NDSMI Hapke. The performance of $N D S M I_{\text {Hapke }}$ was validated by 195 sets of SMC and laboratory spectral data from Yitong County, Jilin province. The results show that the simplified model has a superior ability to predict the moisture content, and has a better applicability over a wide range of areas. To date, there have been few studies of the physically based soil moisture index. To our knowledge, we are the first to extend the Hapke model for the practical soil moisture index. Compared with other empirical indices, this model has a definite physical basis. After simple calibration steps with measured data, a wide range of soil surface moisture can be estimated rapidly according to the $N D S M I_{\text {Hapke }}$. The proposed approach presents a great potential for the retrieval of surface soil moisture on cultivated land.

The penetration depth of optical methods is very limited, and this inherent limitation makes it only able to monitor surface moisture. However, the dramatic fluctuations of soil surface moisture change the overall shape of the reflecting spectra, hence the variations in moisture are considered as the major challenges for the in-field application of soil imaging spectroscopy. The proposed SMR-Hapke 
model could be used as a spectral correction approach to eliminate the influence of moisture, which is beneficial to quantifying other information of interest such as heavy metals, total nitrogen content, organic matter content, or texture. The $N D S M I_{\text {Hapke }}$ index can be used as a sensitive variable to realize the rapid prediction of surface moisture distribution. The soils in the field are influenced by other types of soil surface variation, including vegetation coverage, particle size distribution, dust accumulation, and the formation of physical/biogenic crusts. How to reduce the influence of the above environmental conditions on the optical properties of soil, and how to extend the model for field and large-scale applications, will be the focus of our future research.

Author Contributions: K.T. and Y.Z. conceived and designed the experiments. Y.Z. performed the experiments and analyzed the results. K.T. and Y.Z. wrote the manuscript. X.W., and Y.C. gave comments and suggestions on the manuscript and proofread the document. All authors have read and agreed to the published version of the manuscript.

Funding: This research is supported in part by National Natural Science Foundation of China (No. 41871337).

Conflicts of Interest: The authors declare no conflict of interest.

\section{References}

1. Patel, N.R.; Anapashsha, R.; Kumar, S.; Saha, S.K.; Dadhwal, V.K. Assessing potential of MODIS derived temperature/vegetation condition index (TVDI) to infer soil moisture status. Int. J. Remote Sens. 2009, 30, 23-39. [CrossRef]

2. Seneviratne, S.I.; Corti, T.; Davin, E.L.; Hirschi, M.; Jaeger, E.B.; Lehner, I.; Orlowsky, B.; Teuling, A.J. Investigating soil moisture-climate interactions in a changing climate: A review. Earth Sci. Rev. 2010, 99, 125-161. [CrossRef]

3. Yang, Y.T.; Shang, S.H.; Jiang, L. Remote sensing temporal and spatial patterns of evapotranspiration and the responses to water management in a large irrigation district of North China. Agric. For. Meteorol. 2012, 164, 112-122. [CrossRef]

4. Haubrock, S.N.; Chabrillat, S.; Lemmnitz, C.; Kaufmann, H. Surface soil moisture quantification models from reflectance data under field conditions. Int. J. Remote Sens. 2008, 29, 3-29. [CrossRef]

5. Zhang, C.Y.; Mishra, D.R.; Pennings, S.C. Mapping salt marsh soil properties using imaging spectroscopy. ISPRS J. Photogramm. Remote Sens. 2019, 148, 221-234. [CrossRef]

6. Babaeian, E.; Sadeghi, M.; Jones, S.B.; Montzka, C.; Vereecken, H.; Tuller, M. Ground, Proximal, and Satellite Remote Sensing of Soil Moisture. Rev. Geophys. 2019, 57, 530-616. [CrossRef]

7. Han, N.L.; Chen, S.B.; Wang, Z.J. Retrieval of Bare Surface Soil Moisture from AMSR-E Data. In Proceedings of the 2nd IEEE International Conference on Advanced Computer Control, Shenyang, China, 27-29 March 2010; Volume 2, pp. 67-72.

8. Wigneron, J.P.; Jackson, T.J.; O’Neill, P.; De Lannoy, G.; de Rosnay, P.; Walker, J.P.; Ferrazzoli, P.; Mironov, V.; Bircher, S.; Grant, J.P.; et al. Modelling the passive microwave signature from land surfaces: A review of recent results and application to the L-band SMOS \& SMAP soil moisture retrieval algorithms. Remote Sens. Environ. 2017, 192, 238-262.

9. Kerr, Y.H.; Waldteufel, P.; Richaume, P.; Wigneron, J.P.; Ferrazzoli, P.; Mahmoodi, A.; Al Bitar, A.; Cabot, F.; Gruhier, C.; Juglea, S.E.; et al. The SMOS Soil Moisture Retrieval Algorithm. IEEE Trans. Geosci. Remote Sens. 2012, 50, 1384-1403. [CrossRef]

10. Colliander, A.; Jackson, T.J.; Bindlish, R.; Chan, S.; Das, N.; Kim, S.B.; Cosh, M.H.; Dunbar, R.S.; Dang, L.; Pashaian, L.; et al. Validation of SMAP surface soil moisture products with core validation sites. Remote Sens. Environ. 2017, 191, 215-231. [CrossRef]

11. Bablet, A.; Vu, P.V.H.; Jacquemoud, S.; Viallefont-Robinet, F.; Fabre, S.; Briottet, X.; Sadeghi, M.; Whiting, M.L.; Baret, F.; Tian, J. MARMIT: A multilayer radiative transfer model of soil reflectance to estimate surface soil moisture content in the solar domain (400-2500 nm). Remote Sens. Environ. 2018, 217, 1-17. [CrossRef]

12. Yuan, J.; Wang, X.; Yan, C.X.; Wang, S.R.; Ju, X.P.; Li, Y. Soil Moisture Retrieval Model for Remote Sensing Using Reflected Hyperspectral Information. Remote Sens. 2019, 11, 366. [CrossRef] 
13. Yue, J.B.; Tian, J.; Tian, Q.J.; Xu, K.J.; Xu, N.X. Development of soil moisture indices from differences in water absorption between shortwave-infrared bands. ISPRS J. Photogramm. Remote Sens. 2019, 154, 216-230. [CrossRef]

14. Fabre, S.; Briottet, X.; Lesaignoux, A. Estimation of Soil Moisture Content from the Spectral Reflectance of Bare Soils in the 0.4-2.5 mu m Domain. Sensors 2015, 15, 3262-3281. [CrossRef] [PubMed]

15. Anne, N.J.P.; Abd-Elrahman, A.H.; Lewis, D.B.; Hewitt, N.A. Modeling soil parameters using hyperspectral image reflectance in subtropical coastal wetlands. Int. J. Appl. Earth Obs. Geoinf. 2014, 33, 47-56. [CrossRef]

16. Verstraeten, W.W.; Veroustraete, F.; van der Sande, C.J.; Grootaers, I.; Feyen, J. Soil moisture retrieval using thermal inertia, determined with visible and thermal spaceborne data, validated for European forests. Remote Sens. Environ. 2006, 101, 299-314. [CrossRef]

17. Lei, S.G.; Bian, Z.F.; Daniels, J.L.; Liu, D.L. Improved spatial resolution in soil moisture retrieval at arid mining area using apparent thermal inertia. Trans. Nonferrous Met. Soc. China 2014, 24, 1866-1873. [CrossRef]

18. Chabrillat, S.; Ben-Dor, E.; Cierniewski, J.; Gomez, C.; Schmid, T.; van Wesemael, B. Imaging Spectroscopy for Soil Mapping and Monitoring. Surv. Geophys. 2019, 40, 361-399. [CrossRef]

19. Du, P.; Bai, X.; Tan, K.; Xue, Z.; Samat, A.; Xia, J.; Li, E.; Su, H.; Liu, W. Advances of Four Machine Learning Methods for Spatial Data Handling: A Review. J. Geovisualization Spat. Anal. 2020, 4, 13. [CrossRef]

20. Araya-Lopez, R.A.; Lopatin, J.; Fassnacht, F.E.; Hernandez, H.J. Monitoring Andean high altitude wetlands in central Chile with seasonal optical data: A comparison between Worldview-2 and Sentinel-2 imagery. ISPRS J. Photogramm. Remote Sens. 2018, 145, 213-224. [CrossRef]

21. Zaman, B.; McKee, M.; Neale, C.M.U. Fusion of remotely sensed data for soil moisture estimation using relevance vector and support vector machines. Int. J. Remote Sens. 2012, 33, 6516-6552. [CrossRef]

22. Wang, C.; Wu, X.H.; Li, L.Q.; Wang, Y.S.; Li, Z.W. Convolutional Neural Network Application in Prediction of Soil Moisture Content. Spectrosc. Spectr. Anal. 2018, 38, 36-41.

23. Hassan-Esfahani, L.; Torres-Rua, A.; Jensen, A.; McKee, M. Assessment of Surface Soil Moisture Using High-Resolution Multi-Spectral Imagery and Artificial Neural Networks. Remote Sens. 2015, 7, 2627-2646. [CrossRef]

24. Ishida, T.; Ando, H.; Fukuhara, M. Estimation of complex refractive index of soil particles and its dependence on soil chemical properties. Remote Sens. Environ. 1991, 38, 173-182. [CrossRef]

25. Tan, K.; Wang, H.; Chen, L.; Du, Q.; Du, P.; Pan, C. Estimation of the spatial distribution of heavy metal in agricultural soils using airborne hyperspectral imaging and random forest. J. Hazard. Mater. 2020, 382, 120987. [CrossRef] [PubMed]

26. Tapimo, R.; Atemkeng, C.C.; Kamdem, H.T.T.; Lazard, M.; Yemele, D.; Tchinda, R.; Tonnang, E.H.Z. Bidirectional transmittance and reflectance models for soil signature analysis. Appl. Optics. 2019, 58, 1924-1932. [CrossRef] [PubMed]

27. Tan, K.; Niu, C.; Jia, X.P.; Ou, D.P.; Chen, Y.; Lei, S.G. Complete and accurate data correction for seamless mosaicking of airborne hyperspectral images: A case study at a mining site in Inner Mongolia, China. ISPRS J. Photogramm. Remote Sens. 2020, 165, 1-15. [CrossRef]

28. Cheng, J.L.; Shi, Z.; Li, H.Y. Measurement and simulation of bi-directional reflectance on three zonal soils in the south-east of China. N. Z. J. Agric. Res. 2007, 50, 1177-1185. [CrossRef]

29. Dombrovsky, L.; Randrianalisoa, J.; Baillis, D.; Pilon, L. Use of Mie theory to analyze experimental data to identify infrared properties of fused quartz containing bubbles. Appl. Optics. 2005, 44, 7021-7031. [CrossRef] [PubMed]

30. Bach, H.; Mauser, W. Modelling and model verification of the spectral reflectance of soils under varying moisture conditions. In Proceedings of the International Geoscience and Remote Sensing Symposium, Pasadena, CA, USA, 8-12 August 1994; pp. 2354-2356.

31. Sadeghi, M.; Jones, S.B.; Philpot, W.D. A linear physically-based model for remote sensing of soil moisture using short wave infrared bands. Remote Sens. Environ. 2015, 164, 66-76. [CrossRef]

32. Roosjen, P.P.J.; Bartholomeus, H.M.; Clevers, J.G.P.W. Effects of soil moisture content on reflectance anisotropy-Laboratory goniometer measurements and RPV model inversions. Remote Sens. Environ. 2015, 170, 229-238. [CrossRef]

33. Hapke, B. Theory of Reflectance and Emittance Spectroscopy, 2nd ed.; Cambridge University Press: Cambridge, UK, 2012. 
34. Yang, G.J.; Zhao, C.J.; Huang, W.J.; Wang, J.H. Extension of the Hapke bidirectional reflectance model to retrieve soil water content. Hydrol. Earth Syst. Sci. Discuss. 2011, 15, 2317-2326. [CrossRef]

35. Jacquemoud, S.; Baret, F.; Hanocq, J.F. Modeling spectral and bidirectional soil reflectance. Remote Sens. Environ. 1992, 41, 123-132. [CrossRef]

36. Hapke, B. Bidirectional reflectance spectroscopy 5 . The coherent backscatter opposition effect and anisotropic scattering. Icarus 2002, 157, 523-534. [CrossRef]

37. Labarre, S.; Jacquemoud, S.; Ferrari, C.; Delorme, A.; Derrien, A.; Grandin, R.; Jalludin, M.; Lemaitre, F.; Metois, M.; Pierrot-Deseilligny, M.; et al. Retrieving soil surface roughness with the Hapke photometric model: Confrontation with the ground truth. Remote Sens. Environ. 2019, 225, 1-15. [CrossRef]

38. Ciarniello, M.; Filacchione, G.; D'Aversa, E.; Capaccioni, F.; Nicholson, P.D.; Cuzzi, J.N.; Clark, R.N.; Hedman, M.M.; Ore, C.M.D.; Cerroni, P.; et al. Cassini-VIMS observations of Saturn's main rings: II. A spectrophotometric study by means of Monte Carlo ray-tracing and Hapke's theory. Icarus 2019, 317, 242-265. [CrossRef]

39. Johnson, J.R.; Shepard, M.K.; Grundy, W.M.; Paige, D.A.; Foote, E.J. Spectrogoniometry and modeling of martian and lunar analog samples and Apollo soils. Icarus 2013, 223, 383-406. [CrossRef]

40. Hu, X.X.; Johnston, W.M. Concentration additivity of coefficients for maxillofacial elastomer pigmented to skin colors. Dent. Mater. 2009, 25, 1468-1473. [CrossRef] [PubMed]

41. Hapke, B. Bidirectional reflectance spectroscopy 7 The single particle phase function hockey stick relation. Icarus 2012, 221, 1079-1083. [CrossRef]

42. Segelstein, D.J. The complex refractive index of water. Ph.D. Thesis, University of Missouri-Kansas City, Kansas, MO, USA, 1981.

43. Lei, C. Pure water absorption coefficient measurement after eliminating the impact of suspended substance in spectrum from $400 \mathrm{~nm}$ to $900 \mathrm{~nm}$. J. Remote Sens. 2012, 16, 174-191.

44. Lei, C. Measuring pure water absorption coefficient in the near-infrared spectrum (900-2500 nm). J. Remote Sens. 2012, 16, 192-206.

45. Oltra-Carrio, R.; Baup, F.; Fabre, S.; Fieuzal, R.; Briottet, X. Improvement of Soil Moisture Retrieval from Hyperspectral VNIR-SWIR Data Using Clay Content Information: From Laboratory to Field Experiments. Remote Sens. 2015, 7, 3184-3205. [CrossRef]

46. Sadeghi, M.; Babaeian, E.; Tuller, M.; Jones, S.B. The optical trapezoid model: A novel approach to remote sensing of soil moisture applied to Sentinel-2 and Landsat-8 observations. Remote Sens. Environ. 2017, 198, 52-68. [CrossRef]

47. Lobell, D.B.; Asner, G.P. Moisture effects on soil reflectance. Soil Sci. Soc. Am. J. 2002, 66, 722-727. [CrossRef]

48. Tian, J.; Philpot, W.D. Relationship between surface soil water content, evaporation rate, and water absorption band depths in SWIR reflectance spectra. Remote Sens. Environ. 2015, 169, 280-289. [CrossRef]

49. Galvao, R.K.H.; Araujo, M.C.U.; Jose, G.E.; Pontes, M.J.C.; Silva, E.C.; Saldanha, T.C.B. A method for calibration and validation subset partitioning. Talanta 2005, 67, 736-740. [CrossRef] [PubMed]

(C) 2020 by the authors. Licensee MDPI, Basel, Switzerland. This article is an open access article distributed under the terms and conditions of the Creative Commons Attribution (CC BY) license (http://creativecommons.org/licenses/by/4.0/). 